\title{
Controle do Processo TCPSD para Separação da Mistura
}

\section{Acetonitrila/Benzeno/Metanol}

TCPSD Process Control for Separation of Acetonitrile/Benzene/Methanol Mixture

Control del Proceso TCPSD para la Separación de la Mezcla Acetonitrilo/Benceno/Metanol

Recebido: 23/12/2021 | Revisado: 01/01/2022 | Aceito: 06/01/2022 | Publicado: 09/01/2022

\author{
Lucas de Melo Jurema Guimarães \\ ORCID: https://orcid.org/0000-0001-5031-5412 \\ Universidade Federal de Campina Grande, Brasil \\ E-mail: lucas.guimaraes@eq.ufcg.edu.br \\ Wagner Brandão Ramos \\ ORCID: https://orcid.org/0000-0002-9375-6995 \\ Universidade Federal de Campina Grande, Brasil \\ E-mail: wagner.ramos@eq.ufcg.edu.br
}

\begin{abstract}
Resumo
Visando uma maior economia em custos operacionais, a inclusão de correntes de reciclo e integrações térmicas são rotineiras nos processos químicos, gerando a necessidade de estruturas de controle mais robustas, capazes de impedir perdas devido a distúrbios rotineiros e proporcionar segurança operacional. A separação via Triple-Column PressureSwing Distillation (TCPSD) pode ser utilizada para separar diferentes solventes da indústria de química fina, e devido ao grande número de variáveis envolvidas, juntamente a integrações térmicas e correntes de reciclo, a definição de uma estrutura de controle eficaz se torna um problema complexo. Neste contexto, este trabalho tem como principal objetivo o desenvolvimento e avaliação de estruturas de controle plantwide para o processo TCPSD, utilizado para separação da mistura acetonitrila/benzeno/metanol. Utilizando os softwares Aspen Plus@ e Aspen Plus Dynamics@, foram avaliadas duas estruturas de controle, nas quais as composições dos produtos são controladas por inferência, através do controle da temperatura de pratos sensíveis. A principal diferença entre as duas estruturas é que a Estrutura de Controle 1 possui uma malha de controle de soma dual de temperatura de pratos sensíveis na coluna de baixa pressão, manipulando a razão de refluxo. Ao avaliar os resultados das composições dos produtos ao atingir estado estacionário e valores de ISE, concluiu-se que ambas as estruturas são capazes de controlar distúrbios do tipo degrau na vazão e composição de alimentação do processo. Contudo, observaram-se melhores resultados na Estrutura de Controle 1.

Palavras-chave: TCPSD; Controle plantwide; Controle por inferência.
\end{abstract}

\begin{abstract}
Aiming for greater saving on operating costs, the inclusion of recycle streams and thermal integrations are routine in chemical processes, generating need for more robust control structures capable of preventing losses due to routine disturbances and providing operational safety. The Triple-Column-Pressure-Swing-Distillation (TCPSD) separation can be used to separate different solvents from the fine chemical industry, and due to the large number of variables involved, together with thermal integrations and recycle streams, the definition of an effective control structure becomes a complex problem. At this context, this paper has as main objective the development and evaluation of plantwide control structures for a TCPSD process used to separate the acetonitrile/benzene/methanol mixture. Using the Aspen Plus@ and Aspen Plus Dynamics@ software, two control structures were evaluated, in which the product compositions are controlled by inference, by controlling the temperature of sensitive plates. The main difference between the two structures is that Control Structure 1 has a dual sum control loop of temperature sensitive plates in the low-pressure column, manipulating the reflux ratio. When evaluating the results of compositions of products when reaching steady state and ISE values, it was concluded that both structures are capable of controlling step-type disturbances in flow and composition at feed stream of the process. However, the better results were observed in Control Structure 1.
\end{abstract}

Keywords: TCPSD; Plantwide control; Control by inference.

\section{Resumen}

Con el objetivo de lograr mayores ahorros en los costos operativos, la inclusión de corrientes de reciclaje y las integraciones térmicas son rutinarias en los procesos quimicos, lo que genera la necesidad de estructuras de control más robustas capaces de prevenir pérdidas debido a perturbaciones rutinarias y proporcionar seguridad operativa. La TripleColumn-Pressure-Swing-Distillation (TCPSD) puede ser utilizada para separar diferentes disolventes de la industria química fina y, debido a la gran cantidad de variables involucradas, juntamente con las integraciones térmicas y las corrientes de reciclado, la definición de una estructura de control efectiva se vuelve un problema complejo. En este contexto, este trabajo tiene como objetivo principal el desarrollo y evaluación de estructuras de control plantwide para el proceso TCPSD, utilizadas para separar la mezcla acetonitrilo/benceno/metanol. Utilizando el software Aspen Plus@ 
y Aspen Plus Dynamics@, se evaluaron dos estructuras de control, en las que las composiciones del producto se controlan por inferencia, controlando la temperatura de platos sensibles. La principal diferencia entre las dos estructuras es que la Estructura de Control 1 posee un circuito de control de doble suma de platos sensibles a la temperatura en la columna de baja presión, que manipula la relación de reflujo. Al evaluar los resultados de las composiciones de los productos al alcanzar valores de estado estacionario y de ISE, se concluyó que ambas estructuras son capaces de controlar perturbaciones de tipo escalonado en el flujo y composición de la alimentación del proceso. Aún, se observaron mejores resultados en la Estructura de Control 1.

Palabras clave: TCPSD; Control plantwide; Control por inferencia.

\section{Introdução}

Nos últimos anos, devido a crises econômicas, aumentos nos valores de insumos energéticos (combustíveis e energia elétrica) e alta concorrência estrangeira, torna-se cada vez maior a necessidade de desenvolver processos economicamente viáveis, não afetando a segurança, a qualidade dos produtos, nem o meio-ambiente. Dentro deste contexto, a destilação se destaca por ser um dos processos mais utilizados na indústria para separação de misturas, porém é um processo que demanda um consumo de energia bastante elevado.

Dentre as diversas misturas que existem no universo de processos de separação, alguns possuem um comportamento não usual, onde a Lei de Raoult não representa de forma satisfatória, comumente sendo exemplificada por misturas onde os componentes possuem pontos de ebulição próximos (Seader et al. 2011). Estas misturas formam azeótropos, e quando isto ocorre, torna-se impossível a separação destas misturas através da destilação convencional.

Caso haja, num sistema azeotrópico, a forte presença de forças repulsivas entre as espécies químicas, coeficiente de atividade maiores que a unidade, tem-se um azeótropo homogêneo de mínima fervura. Se, ao invés de repulsão, existir atração entre os componentes químicos, ou seja, coeficientes de atividade inferiores à unidade, tem-se a existência de um azeótropo de máxima fervura (Luyben et al. 2012).

Algumas metodologias podem ser aplicadas para a separação de misturas azeotrópicas, como a destilação extrativa ou destilação por mudança de pressão (pressure-swing). O processo de destilação extrativa, composto por duas colunas de destilação, é amplamente utilizado para separar azeótropos e misturas cujos componentes tenham pontos de ebulição próximos (Seader et al. 2011). Tais processos se valem de um solvente de alto ponto de ebulição sendo introduzido próximo ao topo da primeira coluna para extrair um dos componentes do azeótropo, enquanto o outro componente sai praticamente puro no destilado. Enquanto isso, os demais componentes (primeiro componente do azeótropo e o solvente) saem pela base para alimentar uma segunda coluna onde serão separados em alta pureza, sendo na base a saída do solvente (que voltará a alimentar a primeira coluna através de um reciclo (Luyben et al.2012).

Segundo Luyben (2012), os principais problemas nesse método são a escolha de um solvente apropriado para que o consumo energético e a controlabilidade não sejam afetados.

Um comportamento comum em azeótropos é a variação do ponto de azeotropia ao alterar-se a pressão do sistema. Desta forma, caso a variação deste ponto seja significativa ao aumentar-se a pressão (acima de 5\% mol, como o que acontece nos exemplos da Figura 1), temos azeótropos sensíveis à pressão, onde o processo via pressure-swing pode ser aplicado (Seader et al. 2011). 
Figura 1: Diagramas x vs y de azeótropos de (a) mínimo e (b) máximo pontos de ebulição.

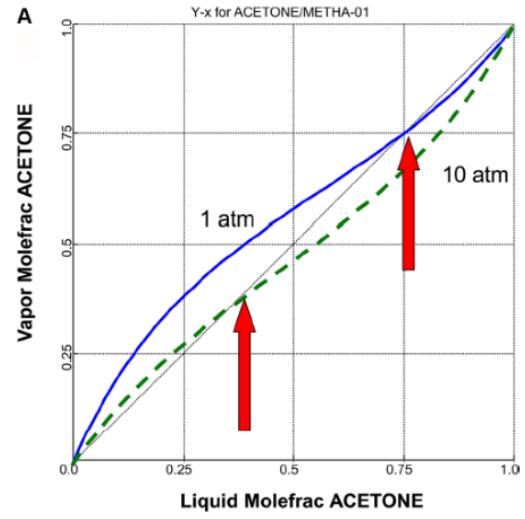

(a)

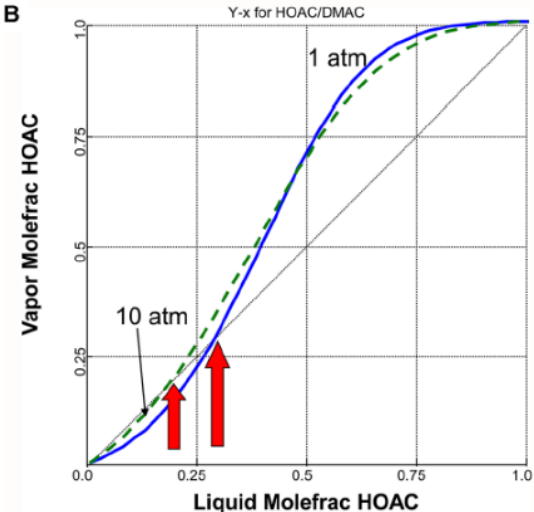

(b)

Fonte: Luyben (2012).

Zhang et al. (2019) explicam que ao utilizar tal método, evita-se a potencial contaminação dos produtos-chave com traços de solventes utilizados. Contudo, deve-se destacar a necessidade de alto consumo energético para manter a pressão em algumas das colunas, que pode ser contornado, para ambas os processos, utilizando integrações térmicas.

Ao estudar o comportamento do ternário tetrahidrofurano/etanol/água bem como uma estrutura de controle plantwide utilizando Aspen Plus Dynamics@ num processo de TCPSD, Yang et al. (2019) obtiveram a sequência de separação mais viável economicamente (água/etanol/tetrahidrofurano com as pressões das colunas em 0,1; 0,52 e $1 \mathrm{MPa}$ ). A estrutura de controle proposta utiliza controle por inferência com diferença dual de temperatura visando redução de desvios e offsets de pureza dos produtos.

Ao trabalhar com o mesmo ternário, Wang et al. (2019) testaram diferentes configurações para a ordem de separação do sistema utilizando comparações entra a aplicação e não-aplicação de cruzamento de limite de curva ou na integração térmica do processo e analisou a economia obtida através deste método. A configuração mais notável foi a utilizando integração parcial na sequência de separação tetrahidrofurano/água/etanol utilizando a técnica de cruzamento de limite de curva, contudo vale destacar que a metodologia foi comprovada como mais rentável em comparação à não aplicação.

Outros três solventes orgânicos muito comuns nas indústrias química e farmacêutica, segundo Zhu et al. (2016), são a acetonitrila, o benzeno e o metanol, devido às suas excelentes propriedades físico-químicas. Logo, torna-se interessante investigar o comportamento deste ternário de azeótropos com comportamento sensível à pressão.

Primeiramente sugerido por Knapp e Doherty (1992) como uma alternativa para a separação de misturas azeotrópicas ternárias sem o uso de destilação extrativa, a TCPSD (Triple-Column Pressure-Swing Distillation) tem como objetivo a separação completa dos três componentes da mistura trabalhando apenas com colunas de destilação em diferentes pressões, o que evita o uso de um solvente. Contudo, é destacável que se necessita de uma avaliação para obter um processo eficiente de separação considerando posição de alimentação, a sequência em que os componentes serão retirados e as pressões ideais de cada coluna, por isso poucos sistemas na literatura foram trabalhados até então.

$\mathrm{Na}$ literatura, tal processo apresenta diversas modificações visando separar a 99,9\% de pureza todos os componentes e visando uma redução cada vez maior de custos. No trabalho de Zhu et al. (2016) foram apresentadas diferentes configurações do processo, com foco nas pressões de operação e sequenciamento das colunas. Em Luyben (2017) a aplicação de controle plantwide é avaliada. Nos trabalhos de Zhu et al. (2017a) e Zhu et al. (2017b) foram avaliados a integração térmica e configurações de reciclo, respectivamente, enquanto Zhang et al. (2019) avaliaram a combinação da integração térmica com o reciclo.

You et al. (2019) estudaram o binário álcool isopropílico/éter diisopropílico tendo em vista a integração térmica parcial 
e total, além do uso de pré-aquecimento das alimentações das colunas (HP-PSD) com seus próprios produtos de base como fluidos de aquecimento. Economicamente falando, a utilização da integração térmica total e pré-aquecimento (HP-PSD) forneceram melhores resultados do que a integração parcial e a total apenas, com uma redução de mais de $31 \%$ no custo total em relação ao processo convencional.

Zhang et al. (2020) analisaram a controlabilidade em processos de PSD com integração térmica parcial em sistemas de máximo ponto de ebulição (etilenodiamina/água). Os autores observaram o efeito de bola de neve (snowball); situação onde, principalmente em processos com reciclo e integração térmica ocorre um acúmulo dinâmico ou de material ou de energia das quais pode afetar de alguma forma negativamente o processo; e o comportamento de estruturas de controle por inferência a serem utilizadas para reduzir os offsets que o acúmulo de material gerado no processo.

De acordo com Silva (2013), toda vez em que há a o desenvolvimento de uma estrutura de controle em que exista uma abordagem em toda planta, tem-se uma estrutura de controle plantwide. O propósito do controle plantwide é prover uma estrutura global para o controle coordenado de muitas variáveis importantes de um processo. Toda essa filosofia de controle surgiu com o objetivo de coordenar diferentes controladores locais, numa tentativa de redução de custos de estocagem de intermediários (Lyman e Georgakis, 1995, apud Hori, 2005). Enquanto Luyben et al. (1998) segue uma abordagem mais heurística e experimental para a seleção de tais estruturas, o trabalho combinado de Skogestad (2000), Halvorsen et al. (2003) e Skogestad (2004) acabaram por gerar uma metodologia matemática focada no uso álgebra linear de forma extensa e minuciosa afim de produzir uma estrutura de controle mais eficiente.

Malhas de controle robustas são cada vez mais necessárias dentro de um processo, sendo um ponto chave tanto na questão da segurança para os colaboradores quanto para a qualidade de especificação dos produtos, ou seja, a pureza deles, visto que, segundo Seborg et al. (2004), o controle em um processo deve atender três necessidades básicas: manter os balanços de massa e energia, atingir a qualidade desejada e atender às restrições do processo. Contudo, apesar de valerem-se de metodologias de controle consideradas de ponta, alguns estudos encontrados na literatura ainda fogem da realidade, quando se utilizam de distúrbios simples para avaliação e sensores que medem diretamente a composição nas correntes de produto, o que não é economicamente viável no campo industrial. Neste sentido, este trabalho se propõe a estabelecer e avaliar estruturas de controle aplicáveis ao processo TCPSD, para a separação da mistura acetonitrila/benzeno/metanol, nas quais as purezas dos produtos são controladas por inferência. Neste trabalho, tem-se como objetivo avaliar estruturas de controle aplicadas ao processo TCPSD para a separação da mistura acetonitrila/benzeno/metanol seguindo como etapas básicas: a simulação do mesmo em regime estacionário no software Aspen Plus; selecionar as variáveis de controle; obter o modelo dinâmico no Aspen Plus Dynamics; implementar as estruturas de controle ao processo e avaliá-las qualitativa e quantitativamente.

\section{Metodologia}

O processo TCPSD (Triple-Column Pressure-Swing Distillation), para a separação da mistura ternária de acetonitrila/metanol/benzeno, foi utilizado como estudo de caso para o desenvolvimento deste trabalho, tomando com o base o trabalho de Zhang et al. (2019). A Figura 2 apresenta os diagramas ternários da mistura acetonitrila/metanol/benzeno, em diferentes pressões, onde é possível observar a formação de azeótropos. Como pode ser notado na Figura 2, os azeótropos formados nessa mistura são sensíveis à mudança de pressão, logo, a TCPSD é uma possibilidade. 
Figura 2: Diagramas ternários da mistura acetonitrila/metanol/benzeno.
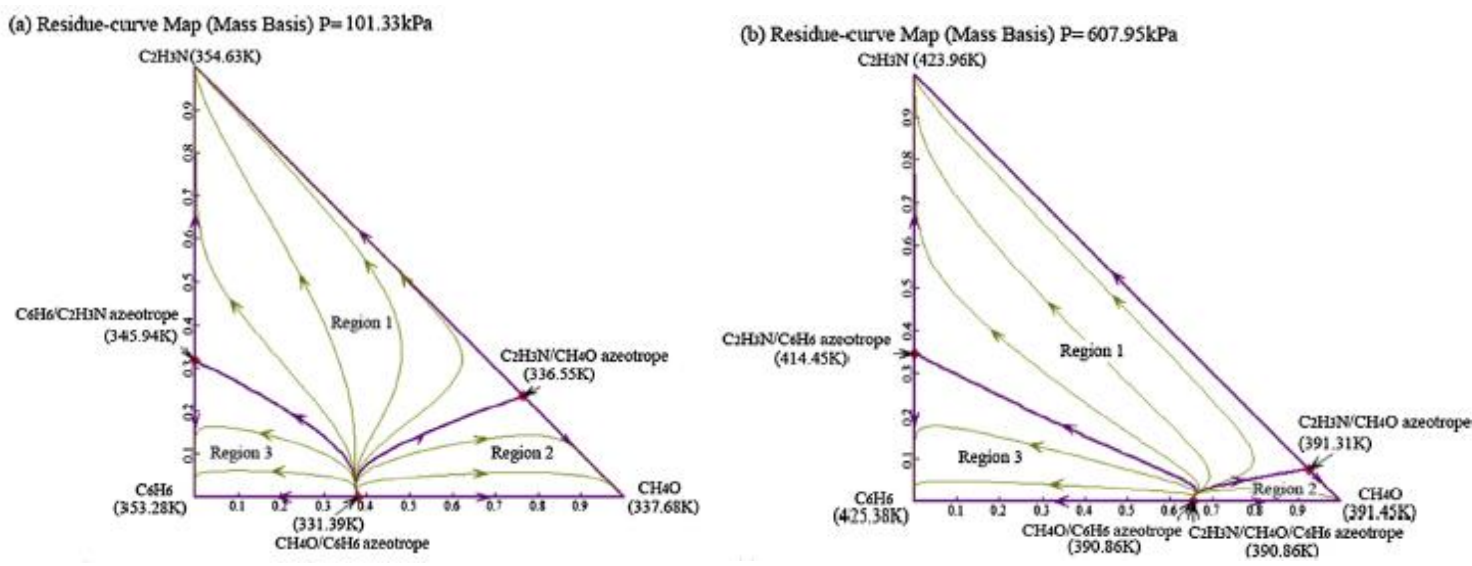

Fonte: Zhu et al. (2016).

\subsection{Simulação em Regime Estacionário}

Para a simulação em regime estacionário, utilizou-se a rotina Radfrac para as três colunas de destilação, visto que é uma rotina robusta e representa bem as colunas de destilação reais. O fluxograma utilizado como base deste trabalho é apresentado na Figura 3. A simulação base utilizou um Splitter para dividir o destilado da coluna de baixa pressão na proporção mássica 6 para 4 , onde $40 \%$ retornava, juntamente com o destilado total da terceira coluna numa rotina de Mixer (havendo o uso de uma bomba para igualar a pressão) para a $1^{\mathrm{a}}$ coluna.

Zhu et al. (2016) realizaram um estudo de qual seria a ordem de separação dos componentes da mistura e quais as pressões de operação de cada uma das colunas do processo para obter composições de base, visto que são todos azeótropos de mínimo ponto de ebulição, em 99,9\%. Zhu et al. (2016) utilizaram parâmetros de interação a partir de regressão para o modelo termodinâmico de Wilson, tal qual demonstrado na Tabela 1.

Tabela 1: Parâmetros de interação via regressão para o método de Wilson.

\begin{tabular}{cccc}
\hline & $\mathrm{CH}_{4} \mathrm{O} / \mathrm{C}_{2} \mathrm{H}_{3} \mathrm{~N}$ & $\mathrm{CH}_{4} \mathrm{O} / \mathrm{C}_{6} \mathrm{H}_{6}$ & $\mathrm{C}_{2} \mathrm{H}_{3} \mathrm{~N} / \mathrm{C}_{6} \mathrm{H}_{6}$ \\
\hline$A_{i j}$ & 0 & $-9,70$ & 0 \\
$A_{j i}$ & 0 & 5,07 & 0 \\
$B_{i j}$ & $-97,08$ & 2399,15 & $-233,59$ \\
$B_{j i}$ & $-262,83$ & $-1965,61$ & $-179,20$ \\
$C_{i j}$ & 0 & 0 & 0 \\
$C_{j i}$ & 0 & 0 & 0 \\
\hline
\end{tabular}

Fonte: Zhu et al. (2016). 
Figura 3: Fluxograma para separação da mistura acetonitrila/metanol/benzeno.

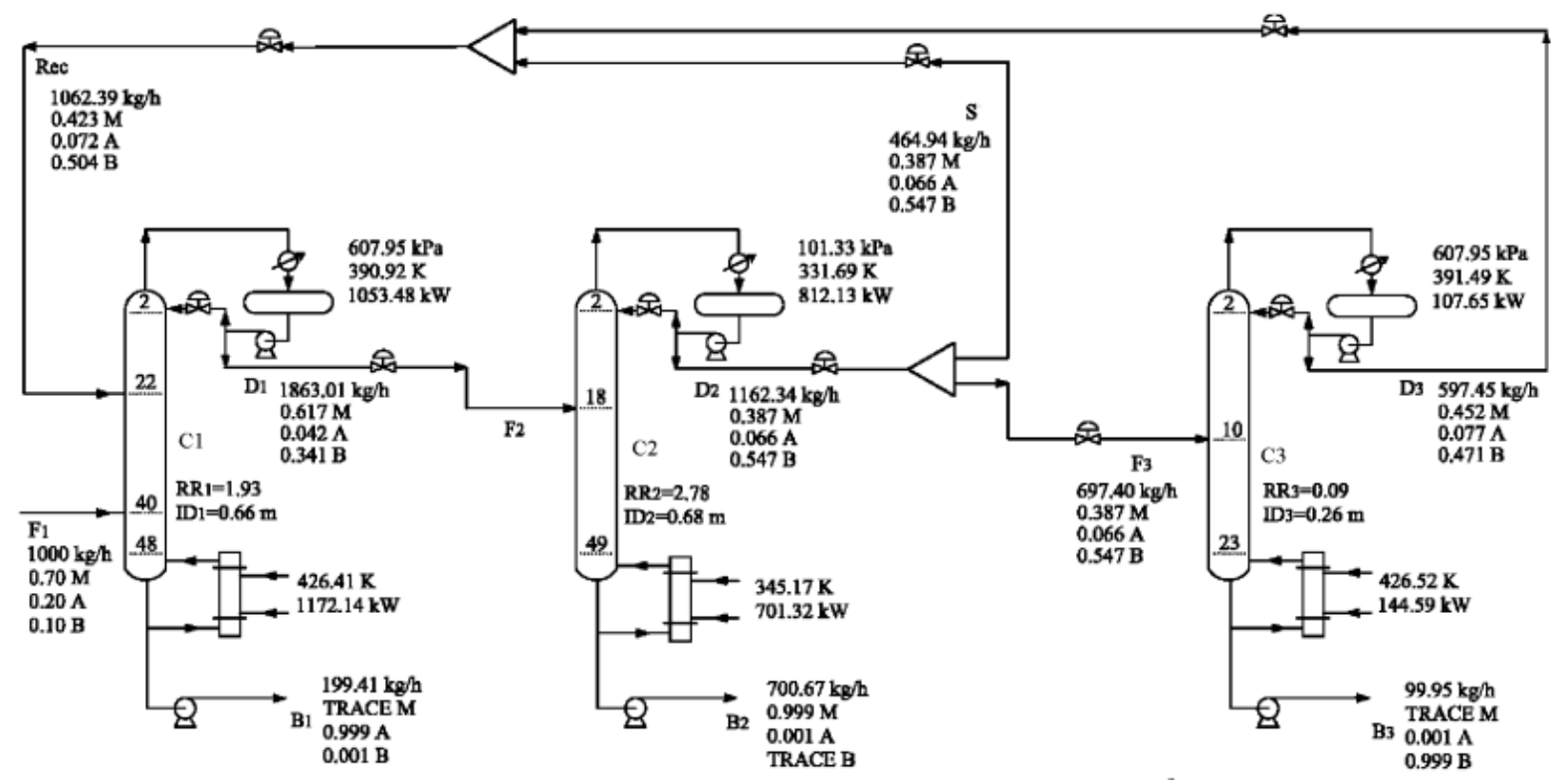

Fonte: Zhu et al. (2017b).

\subsection{Simulação em Regime Transiente}

Para realizar a exportação para o regime transiente, utilizou-se o modo Flow Driven que utiliza as vazões das correntes como variáveis manipuladas na simulação dinâmica.

Neste trabalho, o controle de composição das correntes de produto será feito por inferência. Para isto, faz-se necessário determinar quais estágios das colunas deverão ter a temperatura controlada, de modo a manter o perfil de temperatura da coluna. Para a definição destas variáveis, foi utilizado o critério da sensibilidade, proposta por Luyben (2013).

\subsubsection{Definição da Estrutura de Controle}

As estruturas de controle propostas neste trabalho foram definidas com base na literatura, mais especificamente, a partir dos trabalhos de Luyben (2017) e Zhang et al. (2019), utilizando controle plantwide. A avaliação das estruturas de controle foi realizada aplicando distúrbios do tipo degrau na alimentação, conforme apresentado na Tabela 2. Com o objetivo de enfatizar a eficácia do controle por inferência, os distúrbios foram aplicados em malha aberta e em malha fechada de controle de temperatura.

Tabela 2: Valores dos distúrbios efetuados.

\begin{tabular}{ccccc}
\hline Natureza do & \multirow{2}{*}{ Fluxo (kg/hr) } & \multicolumn{3}{c}{ Composição (wt/wt) } \\
\cline { 3 - 5 } distúrbio & 1000 & Acetonitrila & Metanol & Benzeno \\
\hline Neutro & 1100 & $20 \%$ & $70 \%$ & $10 \%$ \\
Positivo & 900 & $25 \%$ & $65,625 \%$ & $9,375 \%$ \\
Negativo & $15 \%$ & $74,375 \%$ & $10,625 \%$ \\
\hline
\end{tabular}

Fonte: Autores.

Com os distúrbios aplicados após uma hora de simulação, foi possível obter as respostas dinâmicas das composições dos produtos-chave de cada corrente de base, valores das temperaturas dos estágios controlados, níveis dos vasos de refluxo e sump e pressão de topo de cada uma das colunas. 
Outro resultado também obtido foi o cálculo do ISE (Integral do Erro Quadrático) que mede o quão distante está a composição dos produtos-chave dos valores de referência. A partir de tais valores, torna-se possível avaliar de maneira quantitativa qual estrutura de controle gerou melhor resultado diante dos distúrbios aplicados.

Além dos valores de ISE, também foram obtidos os valores das composições dos produtos após a simulação atingir novo estado estacionário. A avaliação conjunta dos valore de ISE e composição final dos produtos contribui para uma conclusão mais assertiva sobre qual estrutura de controle é mais eficaz.

\section{Resultados e Discussão}

\subsection{Simulação em Regime Estacionário}

A Figura 4 apresenta o fluxograma simulado no Aspen Plus, baseado no trabalho de Zhu et al. (2017b). Os dados obtidos na simulação estacionária estão apresentados nas Tabelas 3 e 4.

Figura 4: Fluxograma TCPSD implementado em Aspen Plus.

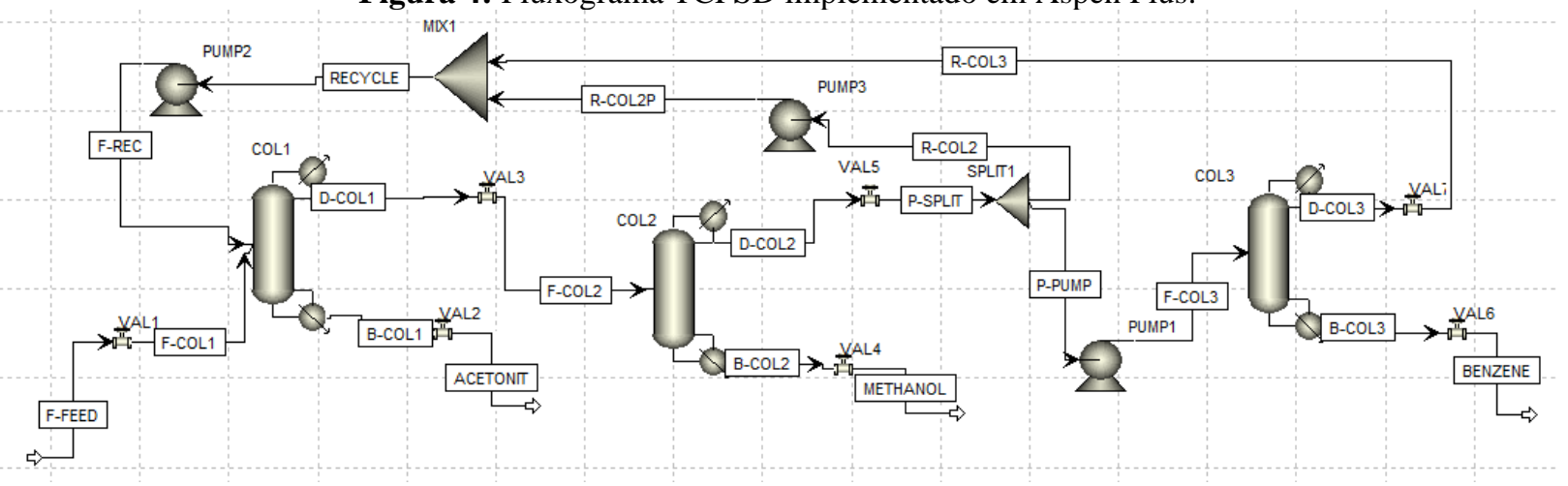

Fonte: Autores.

Tabela 3: Cargas térmicas e razão de refluxo das colunas.

\begin{tabular}{lccc}
\hline & \multicolumn{2}{c}{ Carga Térmica $(\mathbf{k W})$} & \multirow{2}{*}{ Razão de Refluxo } \\
\cline { 2 - 3 } & Refervedor & Condensador & \\
\hline Coluna 1 & 1119,7 & $-1021,91$ & 1,83072 \\
Coluna 2 & 804,009 & $-908,759$ & 3,2 \\
Coluna 3 & 141 & $-102,441$ & 0,0291359 \\
\hline
\end{tabular}

Fonte: Autores.

Tabela 4: Composições e vazões das correntes de processo.

\begin{tabular}{cccccccc}
\hline & F-FEED & D-COL1 & ACETONIT & D-COL2 & METHANOL & D-COL3 & BENZENE \\
\hline Acetonitrila & 0,7000 & 0,6143 & 0,0000 & 0,3841 & 0,9991 & 0,4478 & 0,0000 \\
Metanol & 0,2000 & 0,0408 & 0,9992 & 0,0646 & 0,0009 & 0,0752 & 0,0010 \\
Benzeno & 0,1000 & 0,3449 & 0,0008 & 0,5513 & 0,0000 & 0,4770 & 0,9990 \\
Vazão (kg/hr) & 1000,00 & 1871,68 & 199,41 & 1171,01 & 700,67 & 602,66 & 99,95 \\
\hline
\end{tabular}

Fonte: Autores.

Após alcançar as especificações de produto, conforme verificado na Tabela 4, pode-se iniciar os procedimentos para obtenção do modelo em regime transiente. A partir dos resultados dos cálculos de hidráulica das colunas, realizados pelo próprio 
Aspen Plus, foram obtidos os valores das vazões internas, utilizados para os cálculos dos volumes dos vasos de refluxo e sumps das colunas. Os diâmetros das colunas foram calculados utilizando a ferramenta Column's Internals, do Aspen Plus.

Baseado nas metodologias estabelecidas por Luyben et al. (2010), e usando um tempo de hold up de 5 minutos, tal qual também definido pela literatura, foram obtidos os valores para as dimensões dos vasos para mostrados na Tabela 5 .

Tabela 5: Dimensões dos sumps e vasos de refluxos.

\begin{tabular}{ccccccc}
\hline Coluna & \multicolumn{2}{c}{ Coluna 1 } & \multicolumn{2}{c}{ Coluna 2 } & \multicolumn{2}{c}{ Coluna 3 } \\
\hline Equipamento & Sump & $\begin{array}{c}\text { Vaso de } \\
\text { refluxo }\end{array}$ & Sump & $\begin{array}{l}\text { Vaso de } \\
\text { refluxo }\end{array}$ & Sump & $\begin{array}{c}\text { Vaso de } \\
\text { refluxo }\end{array}$ \\
Diâmetro (m) & 0,625174 & 0,924144 & 0,73 & 0,862355 & 0,252647 & 0,448922 \\
Altura (m) & 5,574801 & 1,848287 & 1,848216 & 1,724711 & 7,5037324 & 0,8978436 \\
\hline
\end{tabular}

Fonte: Autores.

\subsection{Dimensionamento e Estratégias de Controle}

O modelo obtido em regime estacionário, apresentado na Figura 4, foi utilizado para determinação das variáveis controladas, mais especificamente, as temperaturas dos estágios sensíveis, utilizando o critério da sensibilidade, baseado no trabalho de Luyben (2006).

A partir do fluxograma simulado em estado estacionário, foram registrados os perfis de temperatura das colunas 1,2 e 3, e foram aplicados distúrbios positivos e negativos de $0,1 \%$ no valor da variável manipulada de cada coluna (carga térmica do refervedor nas colunas 1, 2 e 3 e razão de refluxo na coluna 2). Os resultados obtidos estão apresentados na Figura 5.

Observa-se na Figura 5(a) que o estágio selecionado para controle de temperatura da Coluna 1 é $38^{\circ}$. Avaliando a Figura 5(b), a metodologia indica o estágio 18 ou o 19 para controle de temperatura da Coluna 2, manipulando a razão de refluxo. Contudo por se tratar de estágios próximos à alimentação, optou-se por controlar a soma das temperaturas dos estágios 8 e 31 . De acordo com a Figura 5(c), o $6^{\circ}$ estágio é o indicado para o controle de temperatura da Coluna 2 utilizando a carga do refervedor como variável manipulada, e para a Coluna 3, o $18^{\circ}$ estágio é o indicado, conforme Figura 5(d).

Figura 5: Variação de temperatura na Colunas 1 (a), Coluna 2 (b) e (c) e Coluna 3 (d).

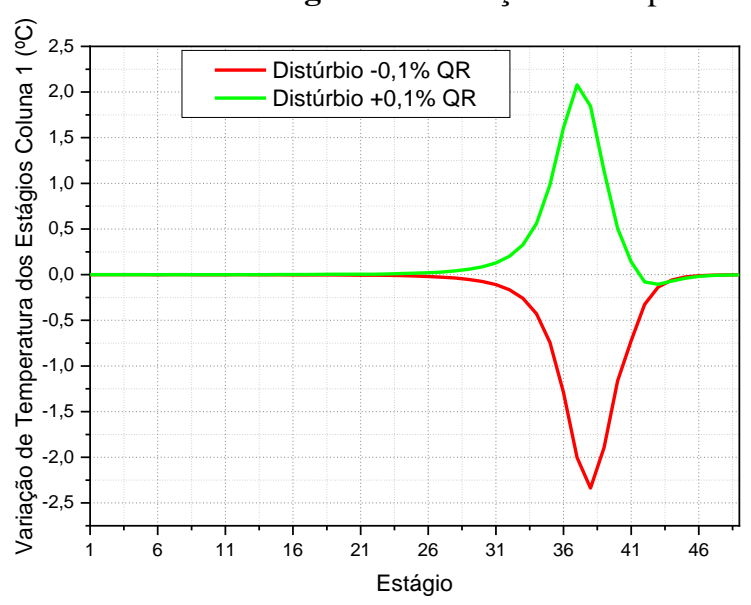

(a)

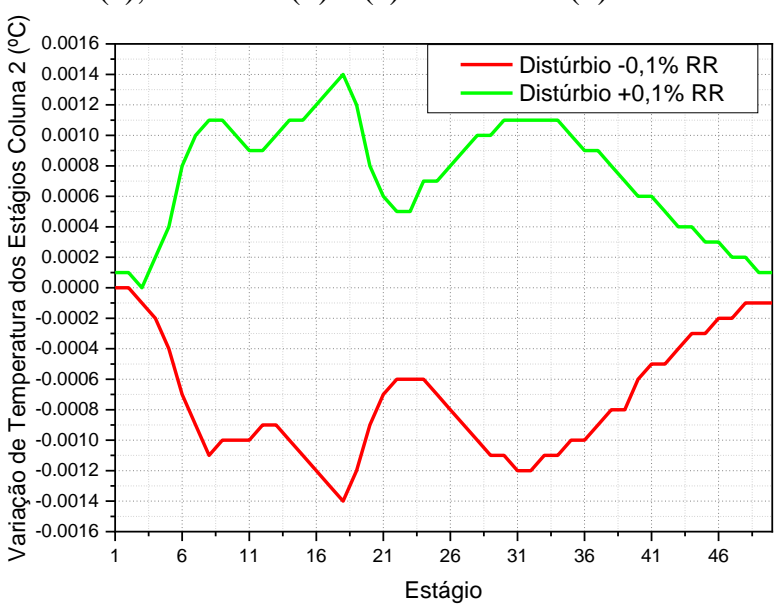

(b) 


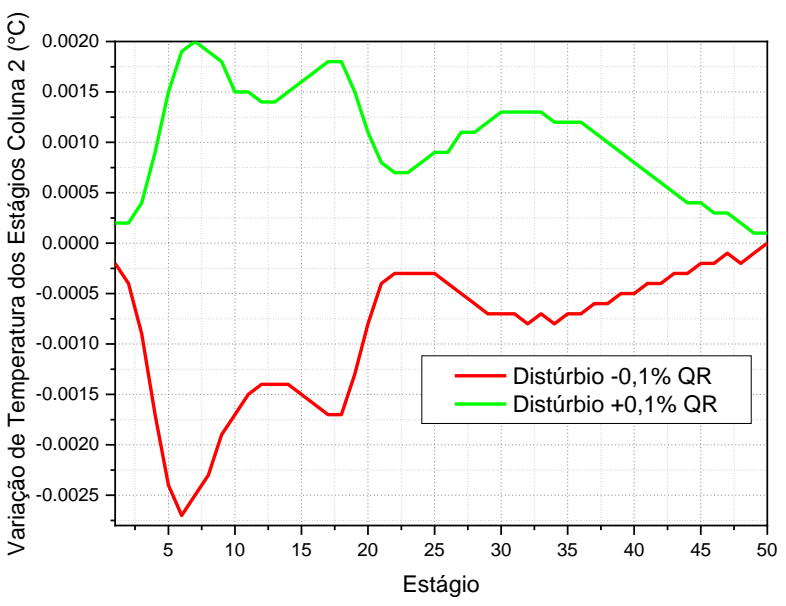

(c)

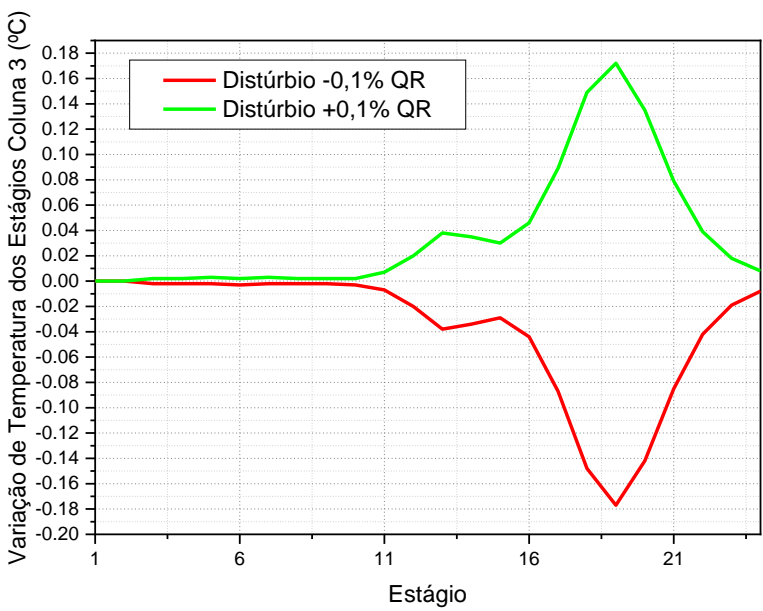

(d)

Fonte: Autores.

Sendo assim, propõe-se duas estruturas de controle onde a diferença entre as duas se dá no controle da segunda coluna. A Estrutura de Controle 1 utiliza um controle de soma de temperatura dual nos estágios 8 e 31 manipulando a razão de refluxo, conforme proposto por Yang et al. (2019), com a finalidade de reduzir desvios e aumentar a velocidade de resposta, enquanto a Estrutura de Controle 2 utilizará um controle de temperatura do estágio 6 manipulando a carga térmica do refervedor.

\subsection{Avaliação das Estruturas de Controle}

Uma vez selecionadas as variáveis controladas e manipuladas de cada coluna de destilação, o passo seguinte foi a implementação dos controladores no Aspen Plus Dynamics. Com base na literatura (Zhang et al., 2019 e Yang et al., 2019), e dos resultados obtidos na seleção dos estágios para controle de temperatura, construiu-se a Estrutura de Controle 1, apresentada na Figura 6.

Figura 6: Estrutura de Controle 1 utilizada para TCPSD.

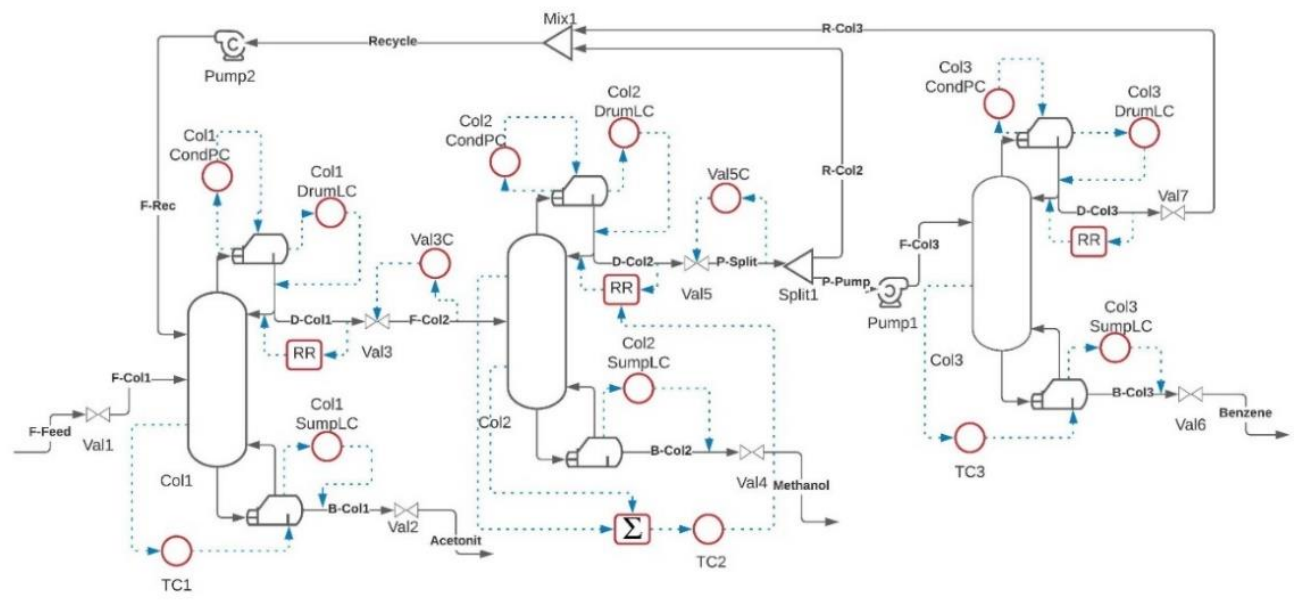

Fonte: Autores.

As demais malhas de controle mostradas na Figura 6, foram estabelecidas com base no trabalho de Skogestad (2006) que utiliza uma configuração de controle LV nas colunas 1 e 3, visto que ambas possuem as cargas térmicas dos refervedores como variáveis manipuladas (indiretamente, V) e possuem um controle proporcional na vazão de refluxo (L), enquanto na coluna 
2, somente os controladores padrões de pressão, nível e o controle somatório de temperatura, manipulando a razão de refluxo, foram utilizados.

Após a implementação dos controladores, foi realizada a sintonia dos parâmetros. Os dados de sintonia dos controladores se encontram na Tabela 6.

Tabela 6: Parâmetros dos controladores da Estrutura de Controle 1.

\begin{tabular}{|c|c|c|c|c|c|}
\hline & $\mathbf{T C}_{1}$ & $\mathbf{T C}_{2}$ & $\mathbf{T C}_{3}$ & $\mathrm{VALC}_{3}$ & VALC $_{5}$ \\
\hline $\begin{array}{c}\text { Variável } \\
\text { Controlada }\end{array}$ & $T_{1,38}$ & $T_{2,8}+T_{2,31}$ & $T_{3,19}$ & $P_{F-C O L 2}$ & $P_{P-S P L I T}$ \\
\hline $\begin{array}{c}\text { Variável } \\
\text { Manipulada }\end{array}$ & $Q_{R 1}$ & $R R_{2}$ & $Q_{R 3}$ & $\begin{array}{l}\text { Abertura } \\
\text { Válvula }\end{array}$ & $\begin{array}{l}\text { Abertura } \\
\text { Válvula }\end{array}$ \\
\hline $\begin{array}{l}\text { Alcance de } \\
\text { Transmissor }\end{array}$ & $0-260,64^{\circ} \mathrm{C}$ & $0-267,47^{\circ} \mathrm{C}$ & $0-299,94^{\circ} \mathrm{C}$ & $0-2,38$ bar & $0-1,02$ bar \\
\hline $\begin{array}{l}\text { Alcance de } \\
\text { Saída de } \\
\text { Controlador }\end{array}$ & $0-2239,41 \mathrm{~kW}$ & $0-6,4$ & $0-282 \mathrm{~kW}$ & $0-100 \%$ & $0-100 \%$ \\
\hline $\begin{array}{l}\text { Ganho } \\
\text { Tempo }\end{array}$ & 0,460734 & 17,088127 & 1,589999 & 0,167951 & 0,586965 \\
\hline $\begin{array}{c}\text { Integrativo } \\
\text { (min) } \\
\text { Tempo }\end{array}$ & 5,674658 & 7,879293 & 3,026681 & 1,200062 & 1,200132 \\
\hline $\begin{array}{c}\text { Derivativo } \\
(\mathrm{min})\end{array}$ & 0,559699 & 0,926067 & 0,270265 & 0,300015 & 0,300033 \\
\hline
\end{tabular}

Fonte: Autores.

Para a Estrutura de Controle 2, seguiu-se estritamente o trabalho de Luyben (2017) para fins comparativos com algo já existente na literatura. A Figura 7 abaixo ilustra a Estrutura de Controle 2.

Figura 7: Estrutura de Controle 2 para TCPSD.

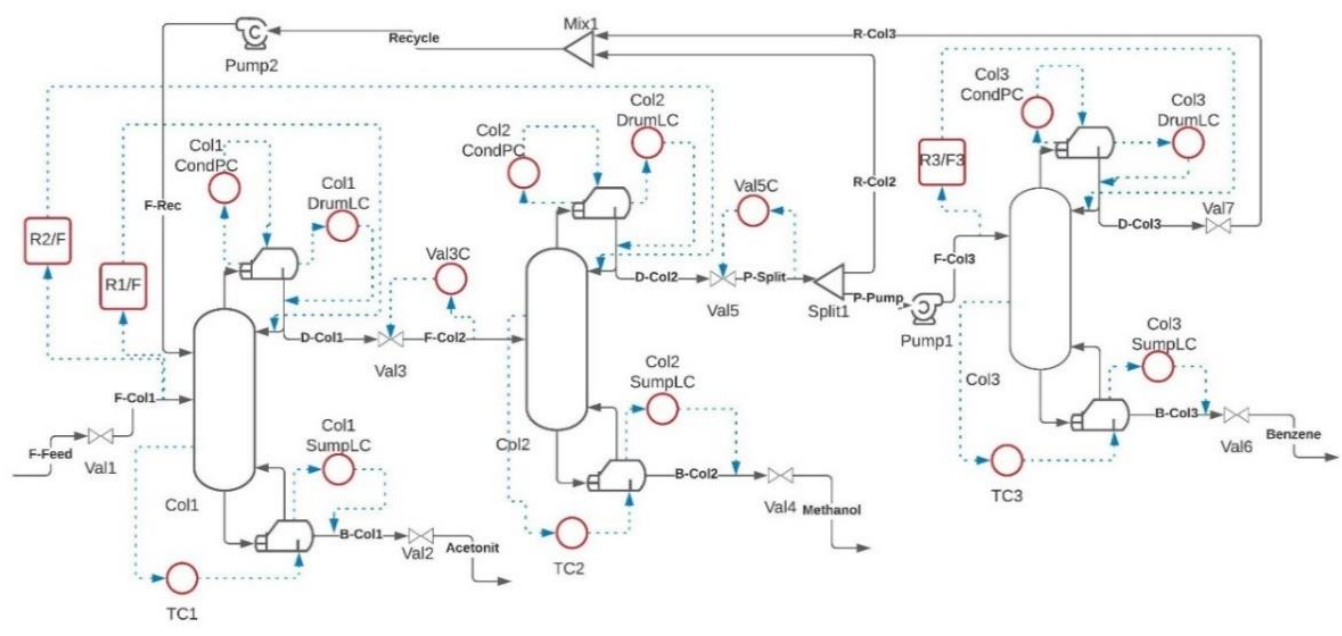

Fonte: Autores.

A Estrutura de Controle 2 controla a razão alimentação/refluxo, relacionando a alimentação do processo com as colunas 1 e 2 e na coluna 3 com a alimentação da mesma. O que diferencia a Estrutura de Controle 2 com a proposta no trabalho de Luyben (2017) é o controle das composições dos produtos por inferência (sem o uso de analisadores online). Os dados de sintonia dos parâmetros dos controladores da Estrutura de Controle 2 estão apresentados na Tabela 7. 
Tabela 7: Parâmetros dos controlados da Estrutura de Controle 2.

\begin{tabular}{|c|c|c|c|c|c|}
\hline & $\mathrm{TC}_{1}$ & $\mathbf{T C}_{2}$ & $\mathrm{TC}_{3}$ & VALC $_{3}$ & VALC $_{5}$ \\
\hline $\begin{array}{c}\text { Variável } \\
\text { Controlada }\end{array}$ & $T_{1,38}$ & $T_{2,6}$ & $T_{3,19}$ & $P_{F-C O L 2}$ & $P_{P-S P L I T}$ \\
\hline $\begin{array}{c}\text { Variável } \\
\text { Manipulada }\end{array}$ & $Q_{R 1}$ & $Q_{R 2}$ & $Q_{R 3}$ & $\begin{array}{l}\text { Abertura } \\
\text { Válvula }\end{array}$ & $\begin{array}{c}\text { Abertura } \\
\text { Válvula }\end{array}$ \\
\hline $\begin{array}{l}\text { Alcance de } \\
\text { Transmissor }\end{array}$ & $0-260,65^{\circ} \mathrm{C}$ & $0-125,71^{\circ} \mathrm{C}$ & $0-299,94^{\circ} \mathrm{C}$ & $0-2,38$ bar & $0-1,02$ bar \\
\hline $\begin{array}{l}\text { Alcance de } \\
\text { Saída de } \\
\text { Controlador }\end{array}$ & $0-2239,41 \mathrm{~kW}$ & $0-1777,78 \mathrm{~kW}$ & $0-282 \mathrm{~kW}$ & $0-100 \%$ & $0-100 \%$ \\
\hline $\begin{array}{l}\text { Ganho } \\
\text { Tempo }\end{array}$ & 0,456878 & 2,99734 & 0,475199 & 0,167951 & 0,586965 \\
\hline $\begin{array}{c}\text { Integrativo } \\
\text { (min) }\end{array}$ & 5,684315 & 6,205248 & 12,128418 & 1,200062 & 1,200132 \\
\hline $\begin{array}{l}\text { Tempo } \\
\text { Derivativo } \\
\text { (min) }\end{array}$ & 0,561136 & 0,544014 & 2,936256 & 0,300015 & 0,300033 \\
\hline
\end{tabular}

Fonte: Autores.

Para os controladores de pressão e nível, utilizou-se para ambas as malhas os valores referenciados por Luyben (2013). Em controladores do tipo PI para pressão e P para nível, apresentados na Tabela 8.

Tabela 8: Parâmetros dos Controladores de Nível e Pressão.

\begin{tabular}{ccc}
\hline Controladores & Nível & Pressão \\
\hline Ganho & 20 & 2 \\
Tempo Integrativo(min) & 12 & 9999 \\
\hline
\end{tabular}

Fonte: Luyben (2013).

\subsection{Avaliações das Estruturas de Controle}

Após as aplicações dos distúrbios, foram obtidas as respostas dinâmicas das principais variáveis controladas do processo, mais especificamente, composição dos produtos e temperatura dos pratos sensíveis. Os resultados foram divididos de acordo com a estrutura de controle e os tipos de distúrbio.

Ao introduzir os distúrbios de vazão no processo TCPSD com Estrutura de Controle 1, foram geradas as respostas dinâmicas da composição referentes aos produtos de base e temperaturas dos pratos sensíveis. Estes resultados estão apresentados na Figura 8.

Avaliando as Figuras 8a, 8b e 8c, é notável que o controle por inferência (malha fechada de temperatura) foi capaz de manter a pureza dos produtos de interesse próximos aos respectivos valores de referência. Após aplicação dos distúrbios, as temperaturas dos pratos sensíveis levam um certo tempo para atingir o setpoint e, com isso, o sistema alcançar novamente o estado estacionário. Por se tratar de controle por inferência, os valores das composições dos produtos irão apresentar desvios em relação ao valore nominais, após o sistema atingir novamente o estado estacionário. A partir dos gráficos apresentados na Figura 8 não é possível quantificar estes desvios da composição, no entanto, observou-se nos históricos da simulação que o maior desvio resultou em uma composição de 0,99788 para o metanol, após distúrbio positivo na vazão, ao atingir 50 horas de simulação. 
Research, Society and Development, v. 11, n. 1, e39811125105, 2022

(CC BY 4.0) | ISSN 2525-3409 | DOI: http://dx.doi.org/10.33448/rsd-v11i1.25105

Figura 8: Respostas dinâmicas após distúrbios de vazão - Estrutura de Controle 1.

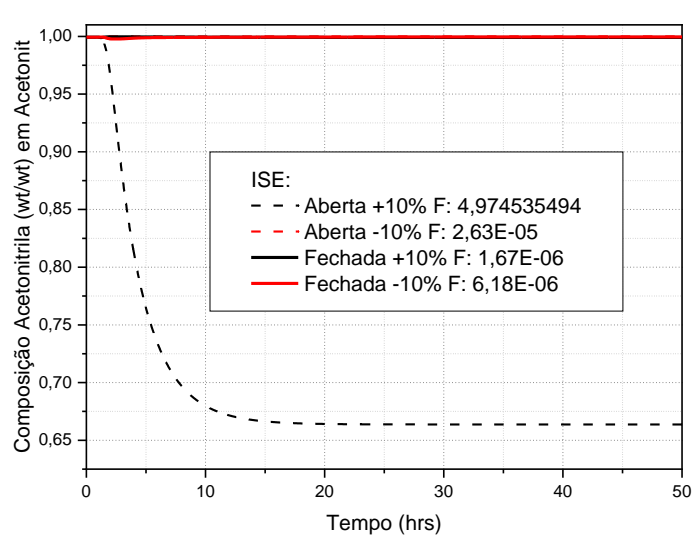

(a)

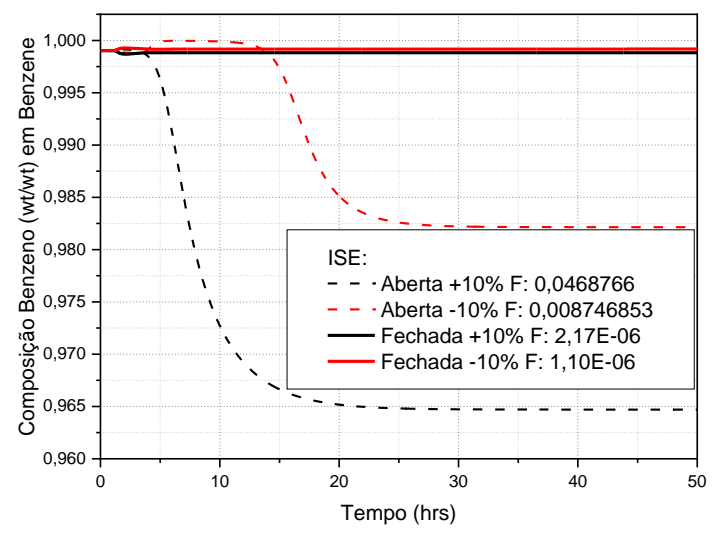

(c)

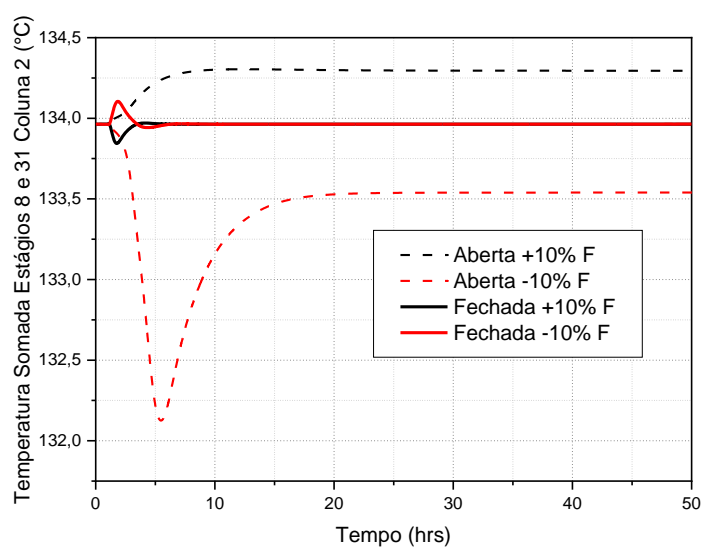

(e)

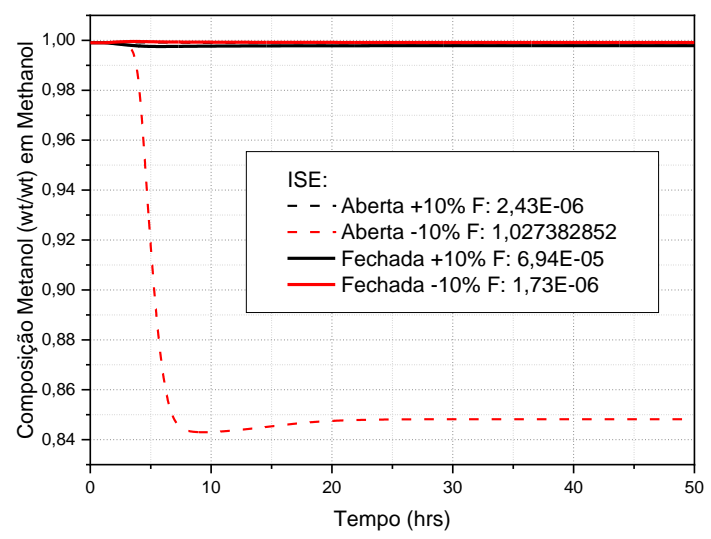

(b)

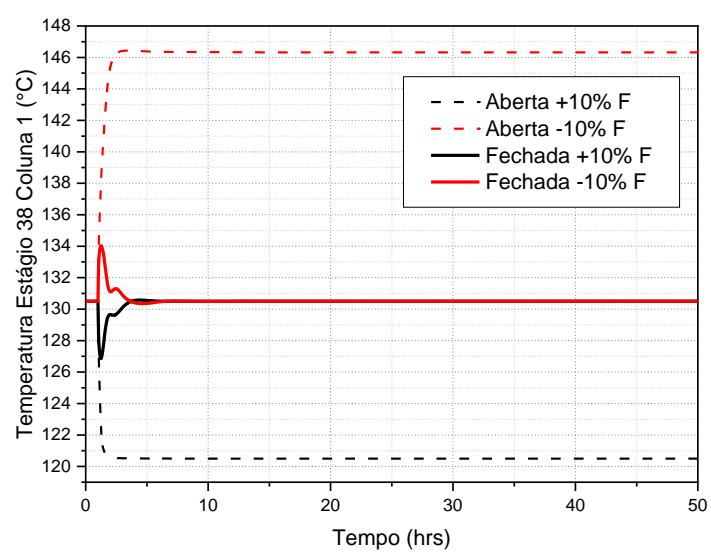

(d)

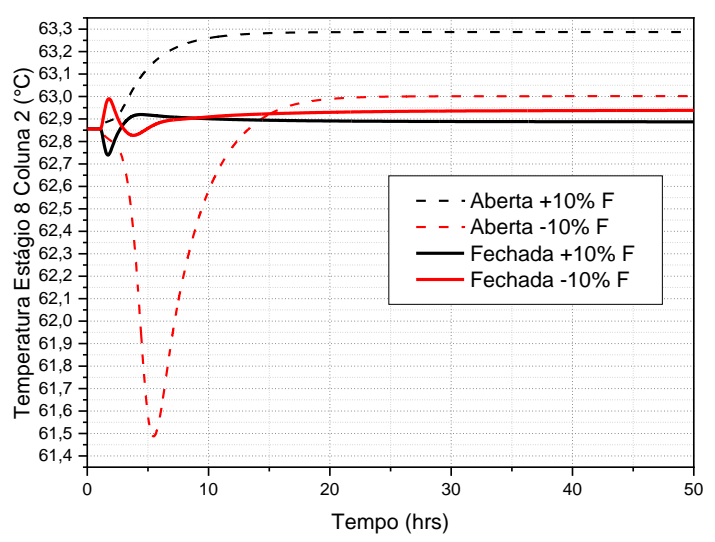

(f) 


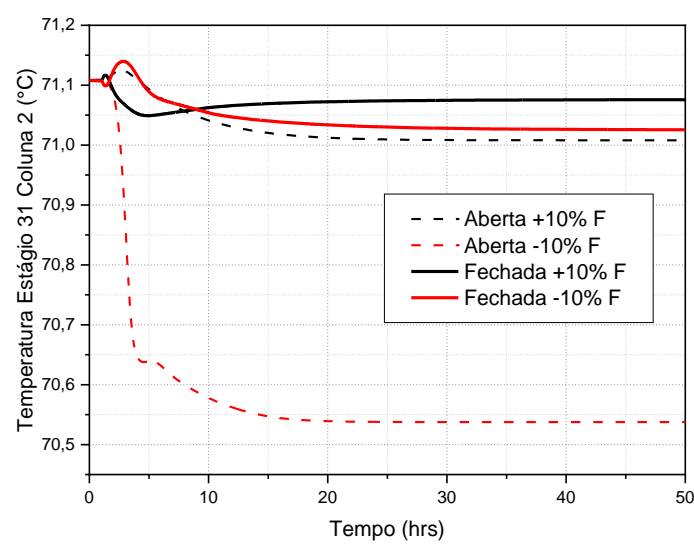

(g)

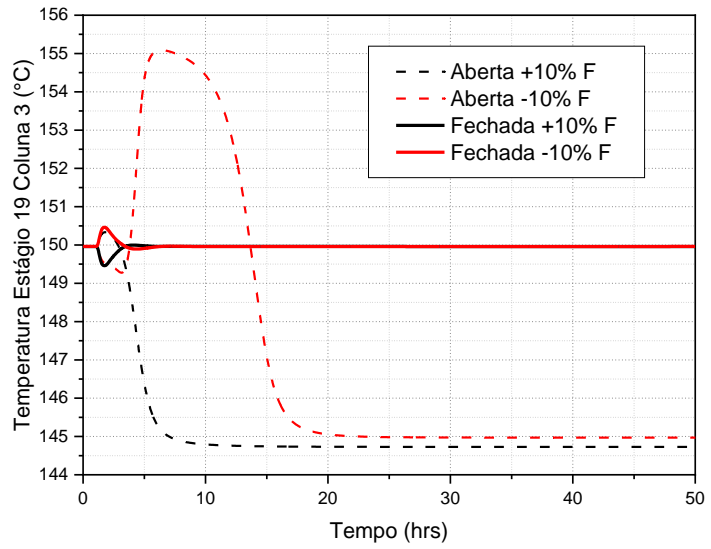

(h)

Fonte: Autores.

Ao avaliar as Figuras 8d, 8e e 8h observam-se rápidas respostas dos controladores, levando em média 3 horas para estabilizar os valores da variável controlada. Contudo, ao observar a decomposição da variável da Figura 8e, representada nas Figuras $8 \mathrm{f}$ e 8g, nota-se uma compensação entre ambas em malha fechada, onde uma tende a reduzir seu valor para compensar o ganho de valor da outra parte. O objetivo da malha de controle que gerou a Figura 8e é controlar o somatório das temperaturas dos estágios 8 e 31 da Coluna 2. Por este motivo, observa-se offset, após distúrbio em malha fechada, nas Figuras 8f e 8g.

A Estrutura de Controle 1 gerou resultados satisfatórios, atingindo o objetivo principal de manter as composições dos produtos próximos aos respectivos valores de referência.

A Figura 9 apresenta as respostas dinâmicas da Estrutura de Controle 1 após distúrbios na composição de alimentação do processo TCPSD. Ao avaliar as respostas dinâmicas em malha aberta de temperatura, percebe-se nitidamente a influência dos distúrbios de composição na pureza dos produtos. Percebe-se também que esta influência diminui ao longo do processo, ou seja, a influência maior é observada na Coluna 1, na qual a composição da acetonitrila cai para aproximadamente 0,70 molar, seguido da Coluna 2, onde a composição do metanol cai para aproximadamente 0,91 molar, e finalmente, na Coluna 3, onde a composição cai para aproximadamente 0,97 molar. Esta mesma tendencia é observada na Figura 8, com a redução da influência do distúrbio de vazão ao longo do processo.

Figura 9: Respostas dinâmicas após distúrbios de composição - Estrutura de Controle 1.

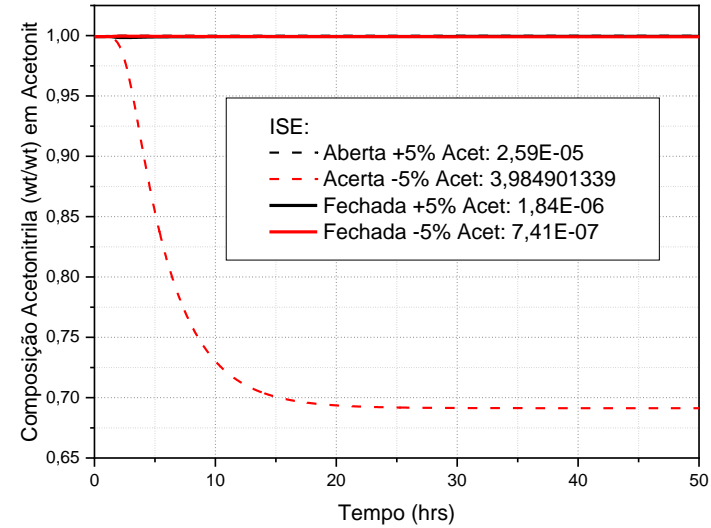

(a)

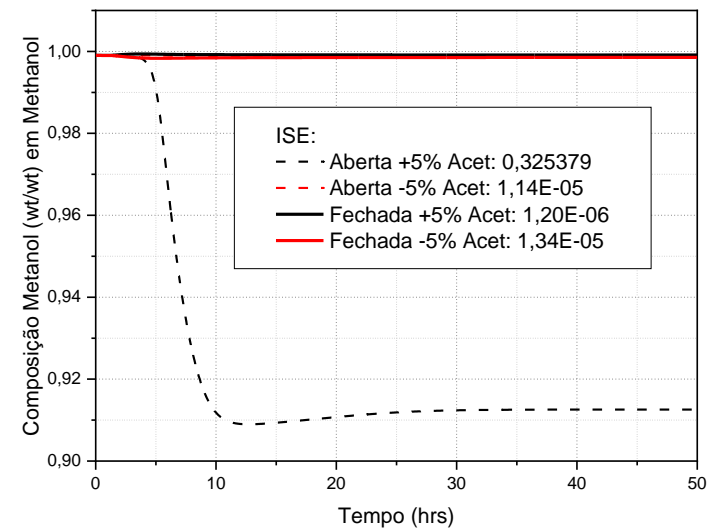

(b) 


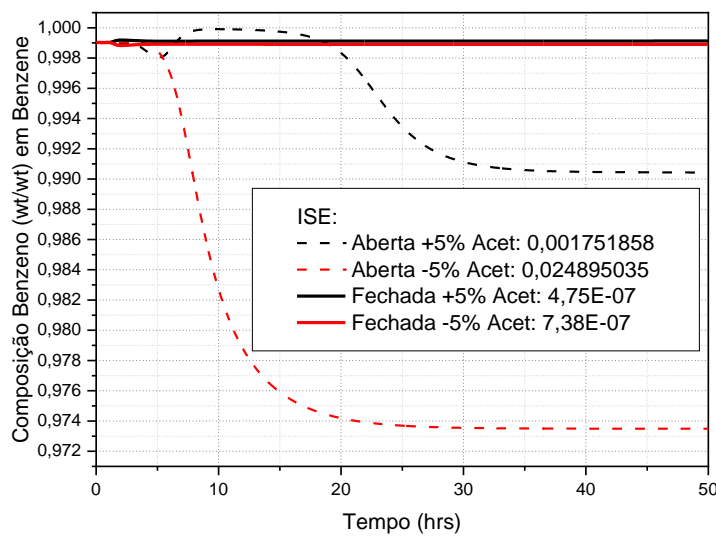

(c)

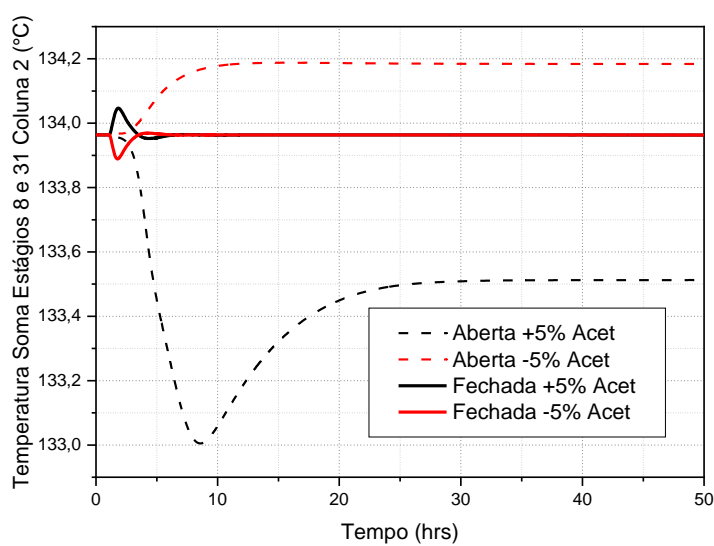

(e)

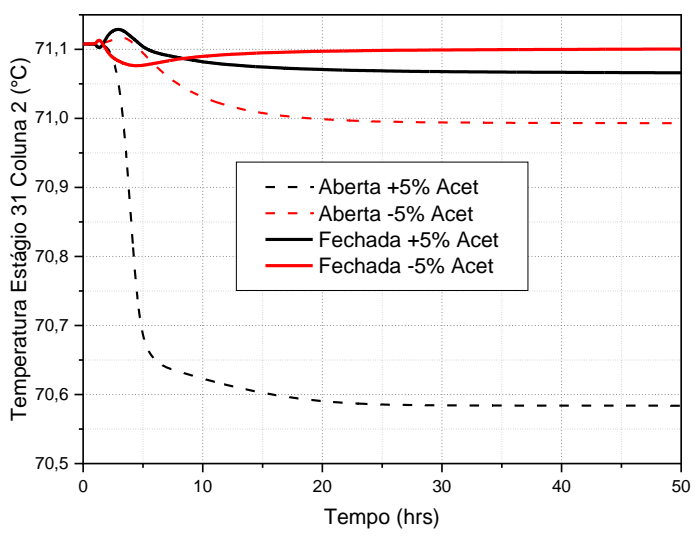

(g)

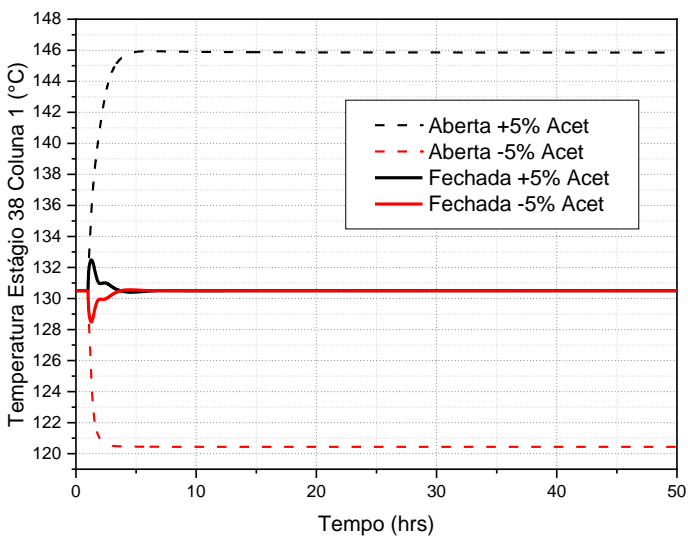

(d)

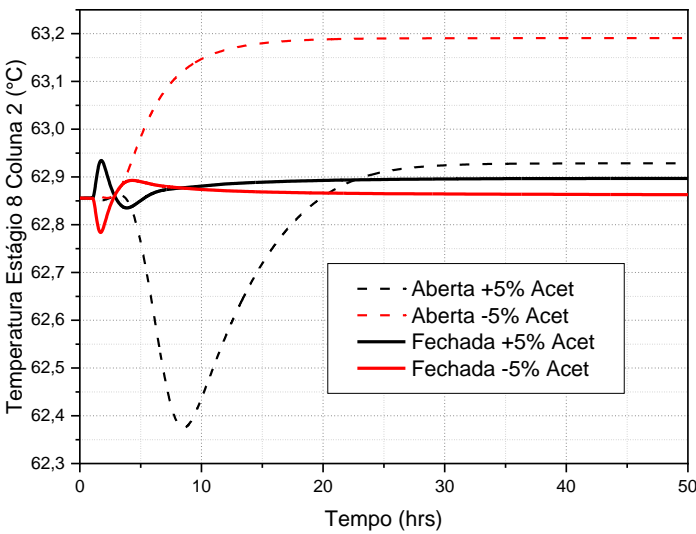

(f)

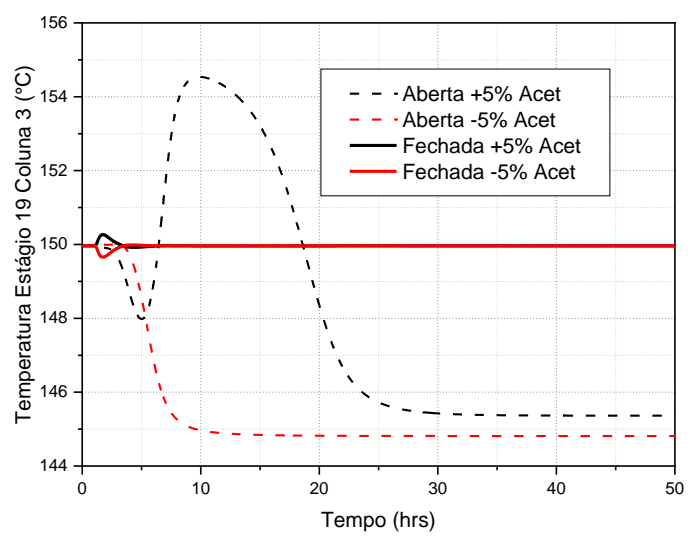

(h)

Fonte: Autores.

Avaliando os históricos das simulações referentes as Figuras 9a, 9b e 9c, observou-se, em malha fechada, que o menor valor encontrado, após atingir novo estado estacionário, foi para o metanol com uma composição 0,998 molar, após distúrbio negativo de composição. As composições da acetonitrila e benzeno permaneceram mais próximos dos valores da especificação $(0,999)$. Estes resultados indicam que a Estrutura de Controle 1 é capaz de realizar um bom controle por inferência da composição dos produtos.

Avaliando as Figuras 9d, 9e e 9h, nota-se tempos de estabilização inferiores a 3 horas, com um comportamento de compensação observado nas Figuras 9f e 9g, tal qual no distúrbio anterior (vazão). 
As repostas dinâmicas das composições dos produtos e temperaturas dos pratos sensíveis, para o sistema TCPSD utilizando a Estrutura de Controle 2, estão apresentadas na Figura 10.

Figura 10: Respostas dinâmicas após distúrbios de vazão - Estrutura de Controle 2.

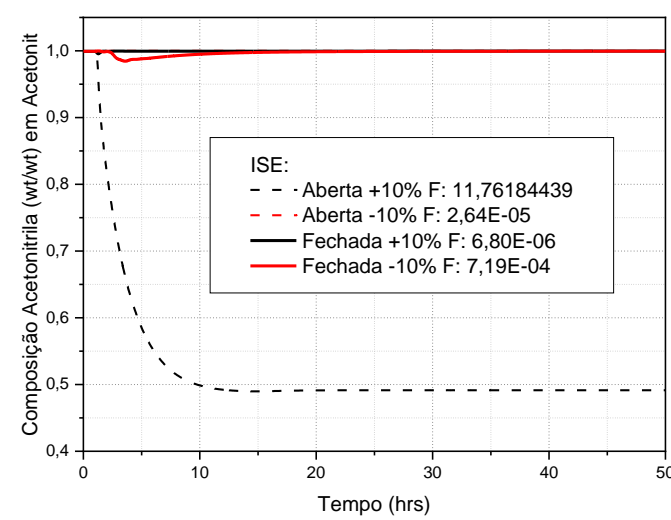

(a)

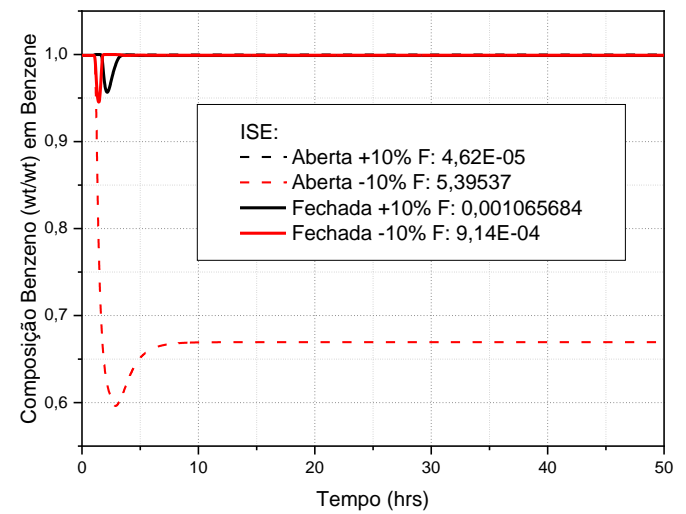

(c)

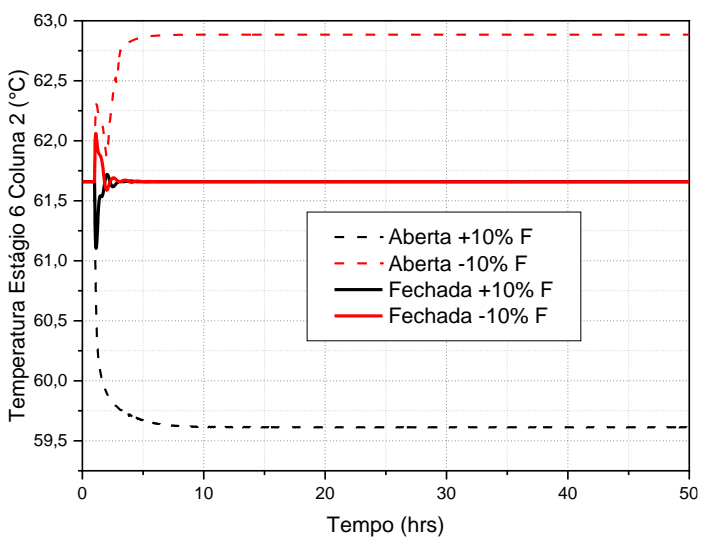

(e)

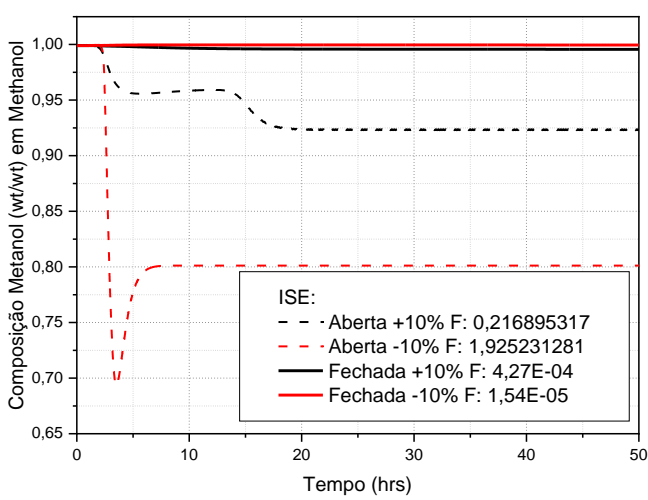

(b)

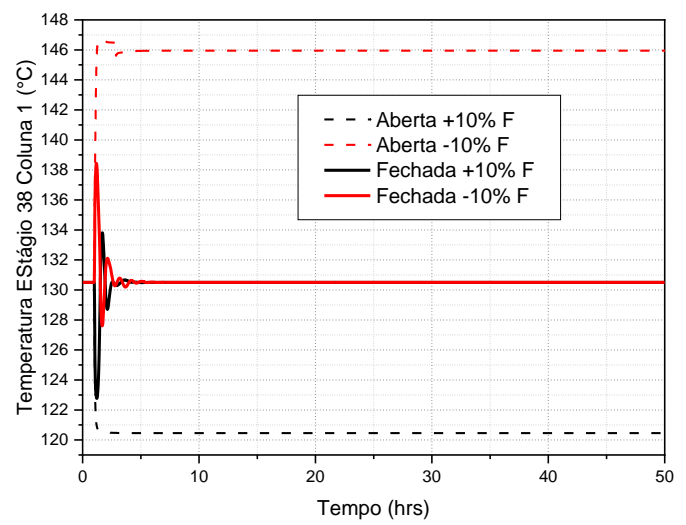

(d)

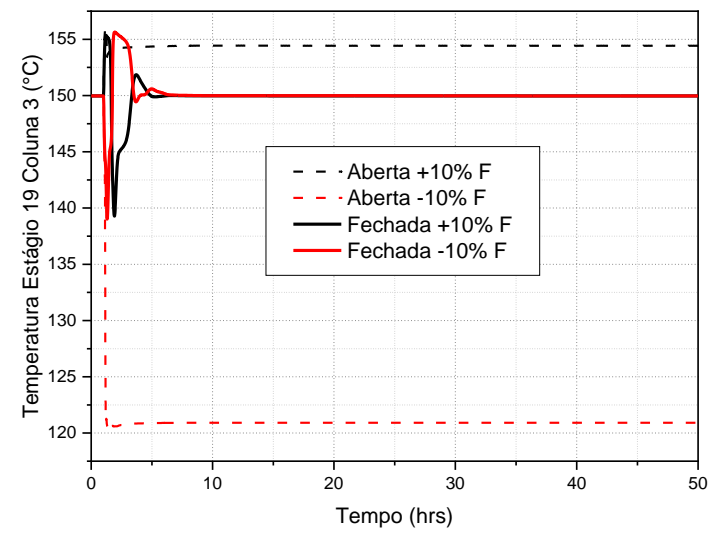

(f)

Fonte: Autores.

Ao avaliar as respostas dinâmicas referentes às composições (Figuras 10a, 10b, e 10c) nota-se a ocorrência de pequenos overshoots, após distúrbios em malha fechada de temperatura; em especial no distúrbio negativo, na composição de acetonitrila, e em ambos os distúrbios, na composição de benzeno. Este comportamento pode afetar o valor final do ISE calculado, apesar de o menor valor de composição apresentado, após atingir estado estacionário em malha fechada, ter sido de 0,995656 para o 
metanol após distúrbio positivo. Observou-se um comportamento semelhante nos distúrbios de malha aberta negativos no metanol e no benzeno, provavelmente causado pela completa secagem do vaso de sump das colunas 1 e 3 observado durante a simulação.

No que diz respeito ao controle de temperatura, evidenciado nas Figuras 10d, 10e e 10f, observou-se um tempo médio de 4,5 horas para a estabilização, sendo um tempo médio superior ao observado na Estrutura de Controle 1, após aplicação do mesmo tipo de distúrbio. Após aplicação de distúrbios de composição no sistema utilizando a Estrutura de Controle 2, foram geradas as respostas dinâmicas apresentados na Figura 11.

Ao avaliar as curvas apresentadas na Figura 11 referentes à composição dos produtos (Figuras $11 \mathrm{a}, 11 \mathrm{~b}$ e $11 \mathrm{c}$ ), observam-se desvios pequenos em relação os valores nominais. Analisando os históricos das simulações, a acetonitrila apresentou o menor desvio após atingir estado estacionário, em malha fechada de temperatura, com um valor de 0,993772 após distúrbio positivo. Para malha fechada após distúrbio negativo, o metanol atingiu o valor de 0,993829 em um tempo relativamente curto (aproximadamente 16 horas). O overshoot apresentado pela composição de benzeno no distúrbio negativo em malha fechada pode ser considerado insignificante, contudo, pode interferir no valor do ISE.

Figura 11: Respostas dinâmicas após distúrbios de composição - Estrutura de Controle 2.

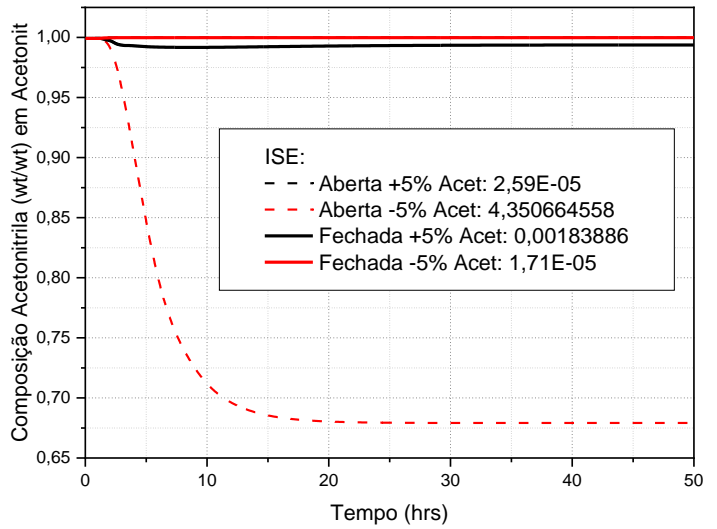

(a)

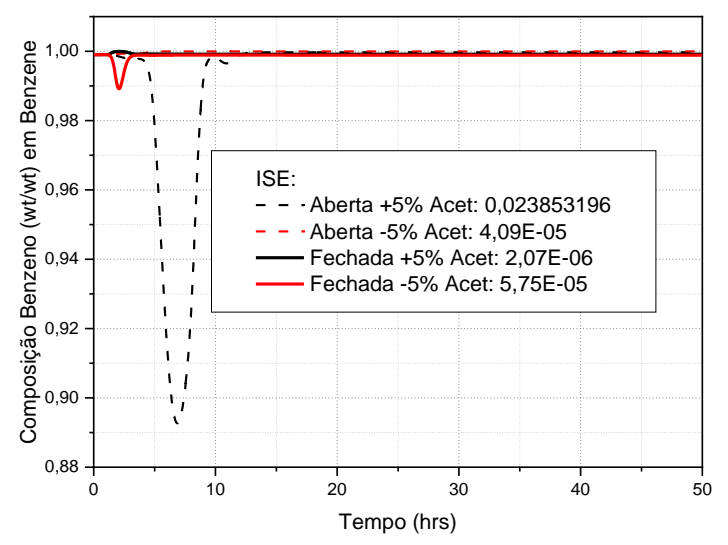

(c)

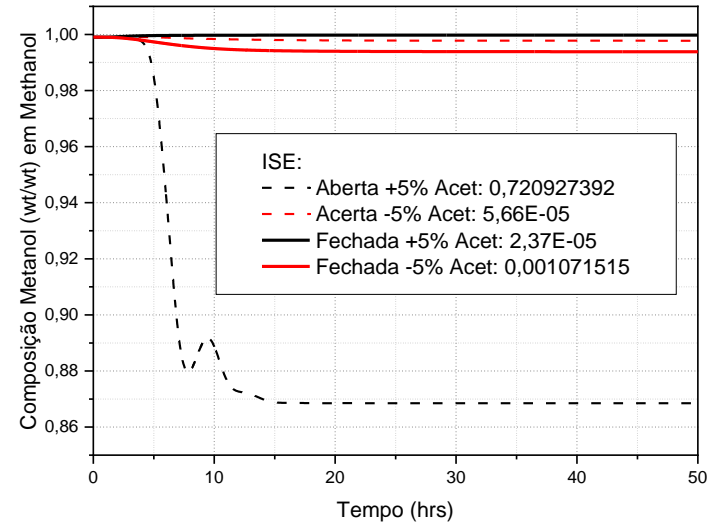

(b)

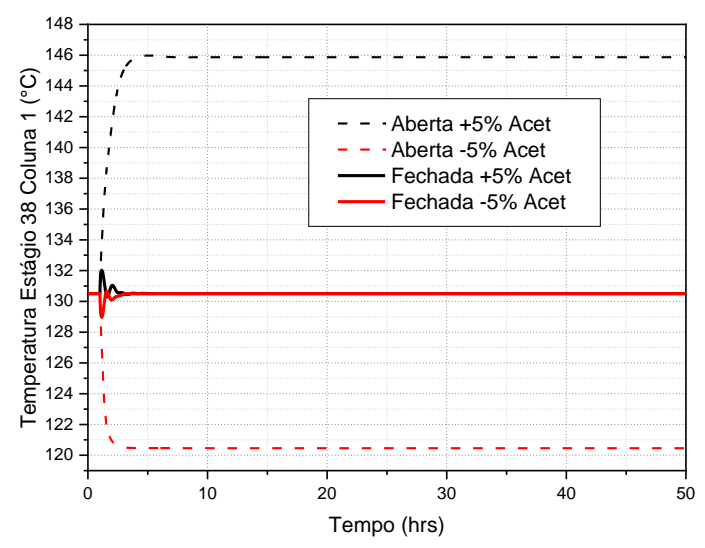

(d) 


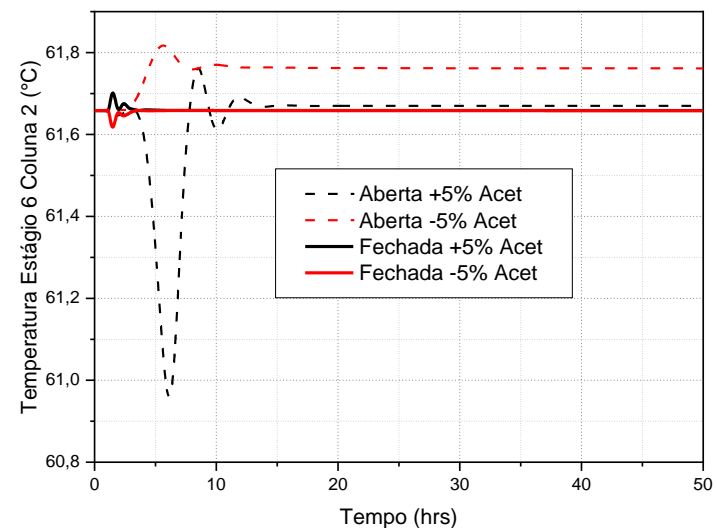

(e)

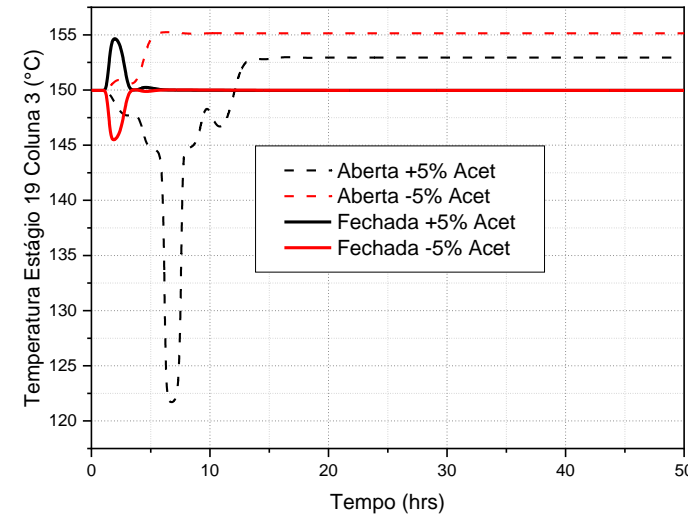

(f)

Fonte: Autores.

Ao avaliar as Figuras 11d, 11e e 11f, nota-se que em menos de 3 horas de simulação as temperaturas estão estabilizadas em malha fechada. Entretanto, no distúrbio positivo em malha aberta, nas colunas 2 e 3, observou-se um overshoot de temperatura anormal que pode ser explicado ao observar os gráficos referentes às pressões das mesmas colunas, pois há uma pequena instabilidade nas pressões que não foi vista de forma tão expressiva em outros distúrbios em malha aberta.

Ao observar as respostas da Estrutura de Controle 1, no que diz respeito ao controle de temperatura da coluna 2, observase, tanto no distúrbio de vazão quanto no de composição respostas mais suaves e com menos oscilações em relação ao apresentado pela Estrutura de Controle 2 para o mesmo equipamento.

Após avaliar o desempenho das estruturas de controle, de forma qualitativa, a partir das respostas dinâmicas, o uso do ISE permite avaliar qual a melhor estrutura de controle de forma quantitativa. Os menores valores de ISE ajudarão a decidir entre as duas Estruturas de Controle analisadas, a que tem o melhor desempenho em termos de obtenção dos produtos com composições próximas aos valores de referência. Para uma melhor visualização, os resultados de ISE obtidos estão sumarizados na Tabela 9.

Tabela 9: Valores de ISE referentes às Estruturas de Controle 1 e 2.

\begin{tabular}{|c|c|c|c|c|c|c|c|c|c|}
\hline & & & & \multicolumn{3}{|c|}{ Estrutura de Controle 1} & \multicolumn{3}{|c|}{ Estrutura de controle 2} \\
\hline & & & Distúrbio & Acetonit & Metanol & Benzeno & Acetonit & Metanol & Benzeno \\
\hline \multirow{4}{*}{ } & \multirow{4}{*}{ 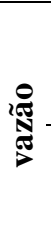 } & Malha & Positivo & 4,974 & $2,43 \mathrm{E}-06$ & 0,047 & 11,762 & 0,217 & $4,62 \mathrm{E}-05$ \\
\hline & & aberta & Negativo & $2,63 \mathrm{E}-05$ & 1,027383 & 0,0087 & $2,64 \mathrm{E}-05$ & 1,925 & 5,395 \\
\hline & & Malha & Positivo & $1,67 \mathrm{E}-06$ & $6,94 \mathrm{E}-05$ & $2,17 \mathrm{E}-06$ & $6,80 \mathrm{E}-06$ & $4,27 \mathrm{E}-04$ & 0,0011 \\
\hline & & Fechada & Negativo & $6,18 \mathrm{E}-06$ & $1,73 \mathrm{E}-06$ & $1,10 \mathrm{E}-06$ & 7,19E-04 & $1,54 \mathrm{E}-05$ & $9,14 \mathrm{E}-04$ \\
\hline \multirow{4}{*}{ 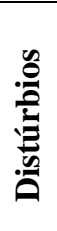 } & \multirow{4}{*}{ 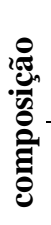 } & Malha & Positivo & $2,59 \mathrm{E}-05$ & 0,325 & 0,0017 & $2,59 \mathrm{E}-05$ & 0,721 & 0,024 \\
\hline & & aberta & Negativo & 3,985 & $1,14 \mathrm{E}-05$ & 0,025 & 4,351 & $5,66 \mathrm{E}-05$ & $4,09 \mathrm{E}-05$ \\
\hline & & Malha & Positivo & $1,84 \mathrm{E}-06$ & $1,20 \mathrm{E}-06$ & $4,75 \mathrm{E}-07$ & 0,0018 & $2,37 \mathrm{E}-05$ & 2,07E-06 \\
\hline & & Fechada & Negativo & $7,41 \mathrm{E}-07$ & $1,34 \mathrm{E}-05$ & $7,38 \mathrm{E}-07$ & $1,71 \mathrm{E}-05$ & 0,0011 & $5,75 \mathrm{E}-05$ \\
\hline
\end{tabular}

Fonte: Autores.

Ao avaliar os dados apresentados na Tabela 9, observa-se que Estrutura de Controle 1 tem uma tendência a gerar desvios menores em relação à Estrutura de Controle 2, com exceção do distúrbio de composição em malha aberta negativo para o benzeno, distúrbio negativo de vazão em malha aberta de temperatura para a acetonitrila e em distúrbio positivo de composição 
positivo em malha aberta de temperatura para a acetonitrila. Entretanto, o interesse principal é na resposta obtida em malha fechada de temperatura. De modo geral, ambas as Estruturas de Controle apresentaram bons resultados.

É importante salientar que a presença de overshoots, após aplicação dos distúrbios, pode interferir no valor final do ISE. Sendo assim, os valores das composições, após atingir novamente o estado estacionário, é um parâmetro que também deve ser levado em consideração para se determinar qual a melhor estrutura de controle, haja visto que o controle por inferência não é capaz de eliminar o desvio da composição após o distúrbio. No entanto, o tempo de simulação de 50 horas utilizado neste trabalho ajuda a minimizar a influência dos overshoots nos valores de ISE. A Tabela 10 apresenta os valores finais das composições dos produtos ao completar 50 horas de simulação.

Tabela 10: Valores finais de composição dos produtos referentes às Estruturas de Controle 1 e 2.

\begin{tabular}{|c|c|c|c|c|c|c|c|c|c|}
\hline & & & & \multicolumn{3}{|c|}{ Estrutura de Controle 1} & \multicolumn{3}{|c|}{ Estrutura de controle 2} \\
\hline & & & Distúrbio & Acetonit & Metanol & Benzeno & Acetonit & Metanol & Benzeno \\
\hline \multirow{4}{*}{ 苋: } & \multirow{4}{*}{ 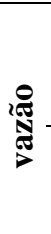 } & Malha & Positivo & 0,66373 & 0,99876 & 0,9647 & 0,49148 & 0,92349 & 1 \\
\hline & & aberta & Negativo & 0,99999 & 0,84822 & 0,98214 & 0,99999 & 0,80115 & 0,66945 \\
\hline & & Malha & Positivo & 0,99903 & 0,99788 & 0,99882 & 0,99956 & 0,99566 & 0,9989 \\
\hline & & Fechada & Negativo & 0,99951 & 0,99912 & 0,99918 & 0,99943 & 0,99956 & 0,99915 \\
\hline \multirow{4}{*}{ 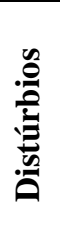 } & \multirow{4}{*}{ 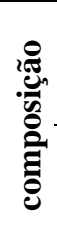 } & Malha & Positivo & 0,99998 & 0,91258 & 0,99043 & 0,99999 & 0,86853 & 0,99971 \\
\hline & & aberta & Negativo & 0,6913 & 0,99845 & 0,97349 & 0,67913 & 0,99776 & 0,99997 \\
\hline & & Malha & Positivo & 0,99938 & 0,99913 & 0,99913 & $\mathbf{0 , 9 9 3 7 7}$ & 0,99975 & 0,99917 \\
\hline & & Fechada & Negativo & 0,99913 & 0,99854 & 0,99891 & 0,99985 & $\mathbf{0 , 9 9 3 8 3}$ & 0,99888 \\
\hline
\end{tabular}

Fonte: Autores.

Foram avaliadas duas estruturas de controle, contendo malhas de controle de composição por inferência, com respostas satisfatórias, tendo como o valor mais distante obtido das especificações, em malha fechada, superior a 0,993 (base mássica), ou seja, bastante próximo do valor de referência que é 0,999.

Sendo assim, pode-se concluir que o controle de composição por inferência apresentou bom desempenho quando aplicado ao sistema TCPSD em questão. As demais malhas de controle (pressão e nível) também apresentaram resultados satisfatórios.

Em relação a comparação entre as duas Estruturas de Controle avaliadas, conclui-se que a Estrutura de Controle 1, que utiliza controle de soma de temperatura dual, gera melhores respostas, mediante distúrbios na vazão e composição, quando comparados aos resultados da Estrutura de Controle 2, que utiliza controle de temperatura manipulando diretamente a carga do refervedor.

O uso do ISE como parâmetro para avaliar a melhor estrutura de controle pode ser influenciado pela ocorrência de overshoots. Sendo assim, o mais indicado é avaliação dos valores de ISE juntamente com o valor da composição dos produtos após atingir novamente o estado estacionário.

Como sugestões para trabalhos futuros para esta área, sugere-se: a aplicação de técnicas como bombas de calor, redes de trocadores de calor e integração térmica para avaliação econômica e avaliação de emissão de gases-estufa, estudos da aplicação de redes neurais para este processo; e uso e metodologias como o kriging para avaliar pontos-chave que ainda precisam de um melhor refino na literatura. 


\section{Considerações Finais}

Foi possível propor duas estruturas de controle, contendo malhas de controle de composição por inferência, com respostas satisfatórias, tendo como o valor mais distante obtido das especificações, em malha fechada, superior a 0,993 (base mássica), ou seja, bastante próximo do valor de referência que é 0,999.

Sendo assim, conclui-se que o controle de composição por inferência apresentou bom desempenho quando aplicado ao sistema TCPSD em questão. As demais malhas de controle (pressão e nível) também apresentaram resultados satisfatórios.

Em relação a comparação entre as duas Estruturas de Controle avaliadas, conclui-se que a Estrutura de Controle 1, que utiliza controle de soma de temperatura dual, gera melhores respostas, mediante distúrbios na vazão e composição, quando comparados aos resultados da Estrutura de Controle 2, que utiliza controle de temperatura clássico baseado no trabalho de LUYBEN (2017).

O uso do ISE como parâmetro para avaliar a melhor estrutura de controle pode ser influenciado pela ocorrência de overshoots. Sendo assim, o mais indicado é avaliação dos valores de ISE juntamente com o valor da composição dos produtos após atingir novamente o estado estacionário.

\section{Referências}

Halvorsen, I. J.; Skogestad, S.; Morud, J. C.; Alstad, V. (2003). Optimal selection of controlled variables. Industrial \& Engineering Chemistry Research, Trondheim, 42, 3273-3284.

Hori, E. S. (2005). Contribuição ao Estudo de Controle "Plantwide": Controle Indireto e Coordenação de Controladores Descentralizados. Tese de Doutorado apresentado a Universidade Federal de São Carlos - UFSCar.

Knapp, J. P., Doherty, M. F. (1992). A New Pressure-Swing-Distillation Process for Separating Homogeneous Azeotropic Mixtures. Industrial \& Engineering Chemistry Research, 31(1), 346-357.

Luyben, W. L.; Tyréus, B. D.; Luyben, M. L. (1998). Plantwide process control. $1^{\text {a }}$ ed. New York: McGraw-Hill.

Luyben, W. L. (2006). Evaluation of criteria for selecting temperature control trays in distillation columns. Journal of Process Control, $16(2), 115-134$.

Luyben, W. L., Chien, I. L. (2010). Design and Control of Distillation Systems for Separating Azeotropes. 1 ed. New York: John Wiley \& Sons.

Luyben, W. L. (2012). Pressure-Swing Distillation for Minimum- and Maximum-Boiling Homogeneous Azeotropes. Industrial \& Engeniering Chemical Research, vol. 51, 10881-10886.

Luyben, W. L. (2013). Distillation, Design and Control Using Aspen Simulation. 2 ed. New York: John Wiley \& Sons.

Luyben, W. L. (2017). Control of a Triple-Column Pressure-Swing Distillation Process. Sep. Purif. Technol., p. 232-244.

Seader, J. D., Henley, E. J., Roper, D. K. (2011). Separation Process Principles: Chemical and Biochemical Operations. 3ed. New York: John Wiley \& Sons.

Seborg, D. E.; Edgar, T. F.; Mellichamp, D. A. (2004). Process dynamics and control. 2nd edition, New York: John Wiley \& Sons.

Silva, S. K. da. (2013). Utilização de uma Ferramenta para Seleção Automática de Estruturas de Controle para Plantas de Processos. Tese de Doutorado apresentado a Universidade Federal de Campina Grande - UFCG.

Skogestad, S. (2000). Plantwide Control: the search for the self-optmizing control structure. Journal of Process Control, Trondheim, $10(5)$, $487-507$.

Skogestad, S. (2004). Control structure design for complete chemical plants. Computers \& Chemical Engineering, Trondheim, 28(1), $219-234$.

Skogestad, S. (2006). The Dos and Don'ts of Distillation Column Control. Chemical Engineering Research and Design, 85, 13-23.

Wang, C., Zhang, Z., Zhang, X., Guang, C., Gao, J. (2019). Comparison of Pressure-Swing Distillation with or without Crossing Curved-Boundary for Separating a Multiazeotropic Ternary Mixture. Separation and Purification Tecnolonogy. vol 220, p 114-125, 2019.

Wang, N., Ye, Q., Chen, L., Zhang, H., Zhong, J. (2021). Improving the Economy and Energy Efficiency of Separating Water/Acetonitrile/Isopropanol Mixture via Triple-Column Pressure-Swing Distillation with Heat-pump Technology. Energy, 215A, 119126.

Yang, A., Shen, W., Wei, S., Dong, L., Li, J., Gerbaud, V. (2019). Design and Control of Pressure-Swing Distillation for Separating Ternary Systems with Three Binary Minimum Azeotropes. AIChE Journal, 65, 1281-1293.

You, X., Ma, T., Qiu, T. (2019). Design and Optimization of Sustainable Pressure-Swing Distillation for Minimum-Boiling Azeotrope Separation Industrial \& Engineering Chemistry Research, 58, 21659-21679. 
Research, Society and Development, v. 11, n. 1, e39811125105, 2022

(CC BY 4.0) | ISSN 2525-3409 | DOI: http://dx.doi.org/10.33448/rsd-v11i1.25105

Zhang, Q., Liu, M. Li, W., Li, C., Zeng, A. (2019). Heat-integrated triple-column pressure-swing distillation process with multi-recycle streams for the separation of ternary azeotropic mixture of acetonitrile/methanol/benzene, Sep. Purif. Technol, 211, 40-53.

Zhang, Q., Zeng, A., Ma, Y., Yuan, X., Gao, J. (2020). Dynamic Control Analyses of Eco-Efficient Partially Heat-Integrated Side-Stream Pressure-Swing Distillation Processes. Sep. Purif.Technol, 239, 115853.

Zhu, Z.; Xu, D.; Liu, X.; Zhang, Z.; Wang, Y. (2016). Separation of acetonitrile/methanol/benzene ternary azeotrope via triple column pressure-swing distillation. Sep. Purif. Technol, 169, 66-77.

Zhu, Z., Xu, D., Jia, H., Zhao, Y., Wang, Y. (2017a). Heat Integration and Control of a Triple-Column Pressure-Swing Distillation Process. Industrial \& Engeniering Chemical Research, 56, 2150-2167.

Zhu, Z., Xu, D., Wang, Y., Geng, X., Wang, Y. (2017b). Effect of multi-recycle streams on triple-column pressure-swing distillation optimization. Chemical Engineering Research and Design, 127, 215-222. 